\title{
Southern San Andreas-San Jacinto fault system slip rates estimated from earthquake cycle models constrained by GPS and interferometric synthetic aperture radar observations
}

\author{
Paul Lundgren, ${ }^{1}$ Eric A. Hetland, ${ }^{2,3}$ Zhen Liu, $^{1}$ and Eric J. Fielding ${ }^{1}$ \\ Received 7 August 2008; revised 1 December 2008; accepted 15 December 2008; published 21 February 2009.
}

[1] We use ground geodetic and interferometric synthetic aperture radar satellite observations across the southern San Andreas (SAF)-San Jacinto (SJF) fault systems to constrain their slip rates and the viscosity structure of the lower crust and upper mantle on the basis of periodic earthquake cycle, Maxwell viscoelastic, finite element models. Key questions for this system are the SAF and SJF slip rates, the slip partitioning between the two main branches of the SJF, and the dip of the SAF. The best-fitting models generally have a high-viscosity lower crust $\left(\eta=10^{21} \mathrm{~Pa} \mathrm{~s}\right)$ overlying a lower-viscosity upper mantle $\left(\eta=10^{19} \mathrm{~Pa} \mathrm{~s}\right)$. We find considerable trade-offs between the relative time into the current earthquake cycle of the San Jacinto fault and the upper mantle viscosity. With reasonable assumptions for the relative time in the earthquake cycle, the partition of slip is fairly robust at around $24-26 \mathrm{~mm} / \mathrm{a}$ for the San Jacinto fault system and $16-18 \mathrm{~mm} / \mathrm{a}$ for the San Andreas fault. Models for two subprofiles across the SAF-SJF systems suggest that slip may transfer from the western (Coyote Creek) branch to the eastern (Clark-Superstition hills) branch of the SJF from NW to SE. Across the entire system our best-fitting model gives slip rates of $2 \pm 3,12 \pm 9,12 \pm 9$, and $17 \pm 3 \mathrm{~mm} / \mathrm{a}$ for the Elsinore, Coyote Creek, Clark, and San Andreas faults, respectively, where the large uncertainties in the slip rates for the SJF branches reflect the large uncertainty in the slip rate partitioning within the SJF system.

Citation: Lundgren, P., E. A. Hetland, Z. Liu, and E. J. Fielding (2009), Southern San Andreas-San Jacinto fault system slip rates estimated from earthquake cycle models constrained by GPS and interferometric synthetic aperture radar observations, J. Geophys. Res., 114, B02403, doi:10.1029/2008JB005996.

\section{Introduction}

[2] Geological and geodetic based slip rate estimates across the southern San Andreas-San Jacinto fault system contain large variability. Geologic observations across these faults vary by technique and the age of the measured features, while inferences of slip rates based on geodetic observations vary with model assumptions. The southern San Andreas fault (SAF) and San Jacinto fault (SJF) systems accommodate most of the North American-Pacific plate motion from south of Cajon Pass to Baja California (Figure 1). Total relative Pacific-North American plate motion is about $50 \mathrm{~mm} / \mathrm{a}$ averaged over the past 3 Myr [DeMets, 1995; DeMets and Dixon, 1999]. The Elsinore fault to the southwest probably accommodates $<10 \%$ of the plate rate [Petersen and Wesnousky, 1994].

\footnotetext{
${ }^{1}$ Jet Propulsion Laboratory, California Institute of Technology, Pasadena, California, USA.

${ }^{2}$ Seismological Laboratory, California Institute of Technology, Pasadena, California, USA.

${ }^{3}$ Now at Department of Geological Sciences, University of Michigan, Ann Arbor, Michigan, USA.
}

Copyright 2009 by the American Geophysical Union. 0148-0227/09/2008JB005996\$09.00
[3] Geologic estimates of slip rates for the southern SAF and the SJF vary significantly depending on location, method, and the geologic age of the offset being measured. The slip rate of the southern SAF is generally considered to be around $25 \mathrm{~mm} / \mathrm{a}$ at Cajon Pass [Weldon and Sieh, 1985]. At the Indio hills site of Biskra Palms a more recent analysis of alluvial fan offsets and isotope age dating finds a much lower SAF slip rate of $15.9 \pm 3.4 \mathrm{~mm} / \mathrm{a}$ [van der Woerd et al., 2006].

[4] The SJF is thought to have formed over the past 11.5 $\mathrm{Ma}$ as slip transferred from the less favorably oriented SAF through the Banning pass to the more favorable SJF along the Peninsular Ranges batholith [Langenheim et al., 2004; Li and Liu, 2007]. SJF slip rates are generally considered to be $6-23 \mathrm{~mm} / \mathrm{a}$ over the past $50 \mathrm{ka}$ on the basis of offset alluvial fans at Anza [Rockwell et al., 1990], with a more recent study estimating a rate greater than $16 \mathrm{~mm} / \mathrm{a}$ [Rockwell et al., 2006]. North of Anza Kendrick et al. [2002] estimated slip rates greater than $20 \mathrm{~mm} / \mathrm{a}$ over the past $100 \mathrm{ka}$. South of Anza, the SJF splits into several active strands: the Coyote Creek fault is the main western strand of the SJF system, while the Clark fault is the main eastern strand. Recent studies have found significant rates for these two faults, with rates of $10 \mathrm{~mm} / \mathrm{a}$ on the Coyote Creek fault over the past $750 \mathrm{ka}$ [Dorsey, 2002], and $14 \pm 0.7 \mathrm{~mm} / \mathrm{a}$ for the Clark fault [Belgarde and Janecke, 2007]. To the SE, the 


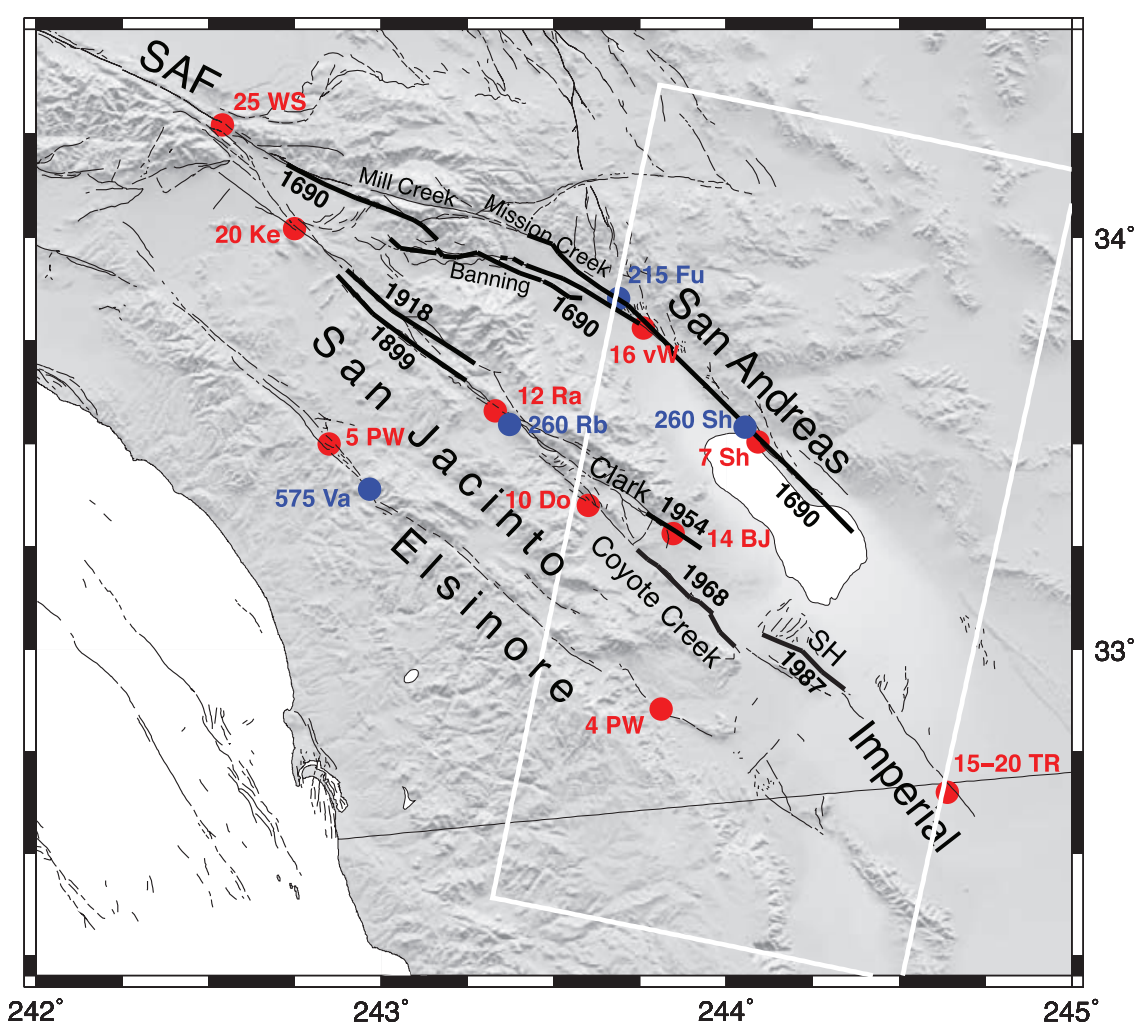

Figure 1. Shaded topographic relief map of the southern San Andreas-San Jacinto fault systems showing rate estimates (red), recurrence time (blue), and their respective reference code. White rectangle outlines InSAR track and frames used in this study. Thin black lines show Quaternary and Holocene age faults. Thick black lines show approximate rupture areas of recent large earthquakes along the southern San Andreas and San Jacinto fault systems. SAF, San Andreas fault (Mojave segment); SH, Superstition hills fault. Reference codes and references are as follows: WS, Weldon and Sieh [1985]; Ke, Kendrick et al. [2002]; Fu, Fumal et al. [2002]; vW, van der Woerd et al. [2006]; Ra, Rockwell et al. [1990]; Rb; Rockwell et al. [2003]; PW; Petersen and Wesnousky [1994]; Va, Vaughan et al. [1999]; Sh, Shifflett et al. [2002]; Do, Dorsey [2002]; BJ, Belgarde and Janecke [2007]; TR, Thomas and Rockwell [1996].

Clark fault is the apparent continuation of the Superstition hills fault. Structural deformation initiation combined with displacement estimates for the SJF near Borrego Springs yields a long-term (>1 Ma) slip rate of 16-21 mm/a [Janecke et al., 2006]. Within this range there are variations with the age interval over which the rates are estimated. These variations in rates over different time intervals have been used to argue that considerable rate changes may have occurred within the SAF and SJF system such that one fault sped up as the other slowed down [Bennett et al., 2004].

[5] Geodetic data require specific model assumptions to derive a present-day fault slip rate. The simplest approach relies on two-dimensional cross-sectional models of geodetic velocity profiles, which allow examination of slip partitioning or material heterogeneity for specific sections of the plate boundary [Malservisi et al., 2001; Johnson and Segall, 2004; Le Pichon et al., 2005; Argus et al., 2005; Hilley et al., 2005; Fay and Humphreys, 2005; Schmalzle et al., 2006; Fialko, 2006; Johnson et al., 2007]. For the SJF-SAF system, the elastic deep slip-driven fault model of Fialko [2006] finds slip rates of $25 \pm 3$ and $19-21 \mathrm{~mm} / \mathrm{a}$ for the SAF and SJF, respectively, whereas the elastic and viscoelastic models of Fay and Humphreys [2005] find rates of about 22-23 and 14-15 mm/a for the SAF and SJF, respectively (Table 1).
Other models constrained by geodetic and other observations (e.g., fault slip measurements, or principal stresses) yield slip rates for the SAF and SJF of $\sim 23-26$ and $\sim 9-15 \mathrm{~mm} / \mathrm{a}$, respectively [Bennett et al., 1996; Meade and Hager, 2005; Becker et al., 2005]. These are somewhat higher (lower) for the SAF (SJF) relative to Fialko's [2006] and Fay and Humphreys's [2005] results, possibly due to differences in model assumptions.

[6] In this paper we use two-dimensional viscoelastic earthquake cycle models in order to estimate fault slip rates from GPS and interferometric synthetic aperture radar (InSAR) profiles across the southern San Andreas-San Jacinto fault system. These interseismic models also depend on the assumed time into the earthquake cycle and the rheological structure. For various assumptions of time into the cycle and rheologic structure, we determine the bestfitting slip rates and explore the trade-offs in the model parameters. This analysis represents somewhat of a hybrid between the studies of Fay and Humphreys [2005] and Fialko [2006]; Fay and Humphreys [2005] used viscoelastic earthquake cycle models to estimate fault slip rates and rheology, and Fialko [2006] used elastic models to explore the SAF dip versus lateral rigidity variations and the location of the currently active strand of the SJF. Fay and Humphreys [2005] 
Table 1. Fault Slip Rate Estimates ${ }^{\mathrm{a}}$

\begin{tabular}{|c|c|c|c|c|c|c|c|c|}
\hline Reference & Elsinore & $\begin{array}{c}\text { Coyote } \\
\text { Creek }\end{array}$ & Clark & $\begin{array}{c}\text { San } \\
\text { Jacinto }\end{array}$ & $\begin{array}{c}\text { San } \\
\text { Andreas }\end{array}$ & Location & $\begin{array}{l}\text { Age } \\
(\mathrm{ka}) \\
\end{array}$ & Comment \\
\hline This study & $2 \pm 3$ & $12 \pm 9$ & $12 \pm 9$ & & $17 \pm 3$ & & & Full profile, weight $1 / 2000$ \\
\hline This study & $5 \pm 3$ & & $24 \pm 3$ & & $15 \pm 2$ & & & Single SJF \\
\hline Bennett et al. [1996] & $6 \pm 2$ & $9 \pm 2$ & & & $26 \pm 2$ & & & GPS data, block model \\
\hline Meade and Hager [2005] & $3 \pm 1$ & $12 \pm 1$ & & & $23 \pm 1$ & & & GPS data, block model \\
\hline Becker et al. [2005] & $4 \pm 7$ & $15 \pm 10$ & & & $23 \pm 8$ & & & CMM3 and stress observations, block model \\
\hline Fay and Humphreys [2005] & $3 \pm 1$ & $15 \pm 1$ & & & $21 \pm 1$ & & & Elastic model \\
\hline Fay and Humphreys [2005] & $3 \pm 1$ & $14 \pm 1$ & & & $23 \pm 1$ & & & Viscoelastic shear zone model \\
\hline Fialko [2006] & & $21 \pm 3$ & & & $25 \pm 3$ & & & Heterogeneous model, vertical SAF \\
\hline Fialko $[2006]$ & & & $19 \pm 3$ & & $25 \pm 3$ & & & Homogeneous model, dipping SAF \\
\hline Weldon and Sieh [1985] & & & & & $25 \pm 4$ & Cajon Pass & 14 & Radiocarbon offset dating \\
\hline van der Woerd et al. [2006] & & & & & $16 \pm 3$ & Biskra Palms & 35 & Cosmogenic dating \\
\hline Kendrick et al. [2002] & & & & $>20$ & & N SJF & 100 & Luminescence dates and uplift modeling \\
\hline Rockwell et al. [1990] & & & & $9-13$ & & Anza & $<50$ & Radiocarbon \\
\hline Rockwell et al. [2006] & & & & $>16$ & & Anza & & \\
\hline Belgarde and Janecke [2007] & & & $14 \pm 1$ & & & & $>600$ & Stratigraphy and paleomagnetic dating \\
\hline Dorsey [2002] & & $\sim 10$ & & & & & $\sim 600$ & Stratigraphy and paleomagnetic dating \\
\hline Le and Oskin [2007] & & $7 \pm 3$ & $4 \pm 2$ & & & & $<10$ & Cosmogenic dating \\
\hline Petersen and Wesnousky [1994] & $4 \pm 1$ & & & & & Coyote Mountains & $<10$ & Soil correlation \\
\hline
\end{tabular}

${ }^{\mathrm{a}}$ Given in $\mathrm{mm} / \mathrm{a}$.

and Fialko [2006] both constrained their models with GPS data, while Fialko [2006] included InSAR data to obtain greater data density across the profile. We address both SAF dip and SJF slip partitioning in the context of vertical and lateral variations in elastic and time-dependent rheology.

\section{Data Analysis}

\subsection{Geodetic Data}

[7] Point geodetic data is taken from the Southern California Earthquake Center (SCEC) Crustal Motion Map version 3 (CMM3) [Shen et al., 2001; Z.-K. Shen et al., The SCEC crustal motion map, version 3.0, 2003, available at http://epicenter.usc.edu/cmm3/]. This model consists of space geodetic observations from campaign and continuous GPS velocities and point geodetic measurements such as electronic distance measurements relative to North America. The CMM3 data has estimates of recent large earthquake coand postseismic deformation effects removed [Shen et al., 2001; Z.-K. Shen et al., The SCEC crustal motion map, version 3.0, 2003, available at http://epicenter.usc.edu/ $\mathrm{cmm} 3 /]$. We have edited the database to remove sites deemed unreliable because of insufficient data and we use only the horizontal components of the velocity estimates because of the large uncertainties in the vertical rates. Since the CMM3 model covers essentially all of southern California we use a subset coincident with the InSAR data coverage described in section 2.2.

\subsection{InSAR Data}

[8] Satellite synthetic aperture radar (SAR) differential interferometry (InSAR) is now a widely used technique for measuring relative surface displacements along the radar line of sight (LOS) between SAR acquisitions, yielding $\sim 100 \mathrm{~m}$ spatial sampling at millimeter level precision over $\sim 100 \mathrm{~km}$ swath widths [Rosen et al., 2000]. We use radar data acquired by the European Space Agency's ERS-1 and ERS-2 satellites between 1992 and 1999 from descending track 356, frames 2925 and 2943, which span the southern San Andreas fault system across the Salton Sea section (Figure 1).

[9] We process the 51 raw ERS SAR scenes between the 28 June 1992 Landers and 16 October 1999 Hector Mine earthquakes with the JPL/Caltech ROI_PAC software package. We formed more than 118 interferograms, on the basis of selecting InSAR pairs with perpendicular baselines less than $200 \mathrm{~m}$ and temporal separations generally less than 3 years to get better coherence. We look down the interferograms in range and azimuth by 4 and 20, respectively, producing roughly $80 \times 80 \mathrm{~m}$ pixels. Topographic and orbit geometry phase delays are estimated and removed from the interferograms using the USGS National Elevation Database at 2-arcsecond spacing and the precise (PRC) orbits. To improve unwrapping, we removed (and later readded) the crustal motion model for southern California of Shen et al. [1996], and masked out lowcoherence areas. Each interferogram was unwrapped using the program SNAPHU [Chen and Zebker, 2001]. Interferograms are then geocoded at 2 -arcsecond $(\sim 60 \mathrm{~m})$ spacing. After culling out interferograms with significant atmospheric artifacts (either because of their severity, or as a consequence, the propensity for these interferograms to contain unwrapping errors) approximately half (61) are retained (Figure 2). Since we are interested in the interseismic deformation rate, we use the SBAS algorithm to solve for the mean velocity and an arbitrary height correction for each interferogram sample [Berardino et al., 2002; Lanari et al., 2004].

[10] The resulting mean velocity map has an apparent residual linear ramp compared to the CMM3 velocity estimates projected into the radar LOS (which varies across the InSAR scene). This ramp is presumably due to residual orbital errors or long-wavelength atmospheric delays that do not cancel out completely in the mean velocity solution, and might be confused with long-wavelength plate boundary deformation. We explored several approaches for removing the residual ramp because small deviations from the actual velocities have significant effects on the model solutions we present below. The easiest way to remove the ramp is to assume an a priori velocity field (i.e., a block model derived velocity at every pixel) and fit the InSAR velocity to that model. This would be acceptable if we can assume the model velocities at longer spatial scales are correct, but it is still model dependent.

[11] An approach that does not explicitly rely on a model, is to assume that there is some region with no ground 


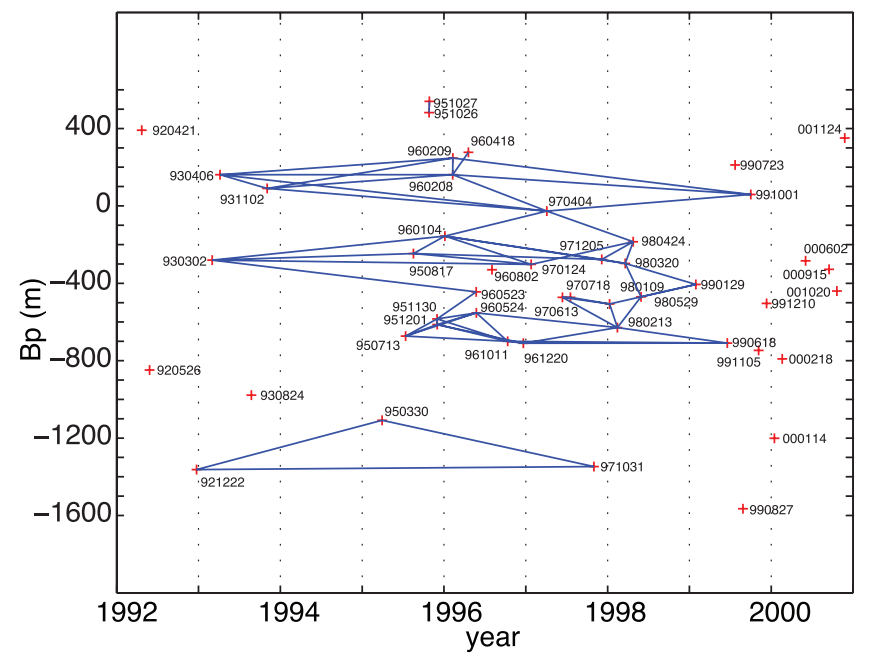

Figure 2. Plot showing European Space Agency ERS-1 and ERS-2 SAR acquisitions available for this study (red plus symbols and date as numeric sequence representing last two digits of the year, followed by the month, and day, i.e., 30 March 1995 is 950330). Blue lines show the actual interferograms used in this study. ERS data acquired either before the Landers (28 June 1992) or after the Hector Mine (16 October 1999) earthquakes were not used.

deformation. For example, Fialko [2006] flattened the InSAR mean velocities for this track (356), by assuming that an area of the Mojave desert to the NE was at zero velocity. This is attractive because it only relies on the InSAR data, however there is still an implicit model assumption in this method. Following this approach, we estimated a ramp in a region of the Mojave, and removed this ramp from the entire InSAR region. We chose the region on the basis of a threshold in the initial solution InSAR velocity map (i.e., all pixels above $0.1 \mathrm{~cm} / \mathrm{a}$ where the initial solution values in the eastern Mojave were significantly positive in LOS velocity). We could adjust the threshold (i.e., the size of the subregion) to get a very close fit to the CMM3 velocities projected onto the InSAR LOS. However, there was still a very small $(\sim 1 \mathrm{~mm} / \mathrm{a})$ discrepancy between the InSAR and the CMM3 data. Specifically, the CMM3 data lay at the "edge" of the InSAR cloud in the southwestern half of the profile, rather than in the middle of the InSAR data. This may be due, for example, to postseismic deformation from the Landers earthquake in the NW corner of the InSAR data that affected the ramp estimate.

[12] Since we do not expect the InSAR velocities to deviate from the GPS velocities at significant distances from the fault, we choose to estimate the ramp directly from the residual InSAR velocities after removing the CMM3 velocities. To do this, we interpolate the CMM3 horizontal velocities using the Matlab griddata function. We then project the interpolated CMM3 velocities onto the InSAR LOS, and remove these from the InSAR velocities. Using least squares, we fit a planar ramp directly from these residual InSAR velocities. The region over which we estimate the ramp could range from the entire InSAR footprint to some small subset of it. In this paper we estimated the ramp over an area that was twice the size of the profile box shown in Figure 3. This ramp approximates long-wavelength orbital and atmospheric errors in the InSAR measurements, and thus we remove it from the InSAR measurements. We use these deramped velocities to constrain our models.

[13] Not surprisingly, as shown in Figure 3, the adjusted velocities show good agreement with the CMM3 data projected into the radar LOS over the SAF normal profile considered in this study. Contained within the InSAR velocity solution are areas with significant deviation from the CMM3 data. These are generally associated with localized hydrologic sources. Since these strong subsidence or uplift signals represent a rather small number of points (though they do add a significant "static" value to the data-model misfit), and attempting to "correct" the data by masking out these areas is rather ad hoc, we leave them in the data for the inverse solutions. The final mean velocities and their standard deviations $(\sim 1-2 \mathrm{~mm} / \mathrm{a}$ for most samples) used in this study are computed by averaging $8 \times 8$ (64 total) pixels of the original $60 \mathrm{~m}$ geocoded velocities for a sampling of $480 \mathrm{~m}$ per pixel.

\section{Earthquake Cycle Modeling}

[14] Relatively simplified two-dimensional earthquake cycle models for infinitely long strike-slip faults (Figure 4) are useful for understanding the effects of viscosity $(\eta)$ on interseismic velocities and their variations within the earthquake cycle [Savage and Prescott, 1978; Hetland and Hager, $2005,2006]$. For rheologies with relaxation times $\left(\tau_{m}=\eta / \mu\right.$ where $\tau_{m}$ is the relaxation time for a material with viscosity $\eta$ and shear modulus $\mu$ ) longer than the earthquake repeat time (i.e., $\tau_{m}>T$, where $T$ is the repeat time), velocity profiles across the fault have relatively small variation throughout the earthquake cycle (Figure 5). As the viscosity decreases velocity profiles show greater variation, with velocities near the fault during the postseismic period greater than the farfield shear velocities, but steadily decreasing to a more linear trend across the fault later in the cycle. Earthquake cycle models can also depend on the assumed distance from the fault where the far-field shear boundary conditions are applied. Savage and Prescott's [1978] solution is driven by creep on the deep extension of the fault, although it is equivalent to a model driven by infinitely far shear [e.g., Hetland and Hager, 2006]. Pollitz [2001] modified the model of Savage and Prescott [1978] by assuming that interseismic velocities only vary within a finite width shear zone, and showed that when $\tau_{m}<T$ and the velocities are fixed at a distance of ten locking depths from the fault, the interseismic velocities differ from Savage and Prescott's [1978] model. In addition to these analytic models, finite element models are commonly used to model interseismic velocities, and they allow for arbitrary shear zone width, as well as variations in fault geometry and material properties [Williams and Richardson, 1991; Fay and Humphreys, 2005].

[15] There are some caveats to the approaches listed above. The analytical models of Savage and Prescott [1978] and Hetland and Hager [2005] are only for a vertical strike-slip fault in an elastic layer over a viscoelastic half-space. Savage and Prescott [1978] only considered periodic sequences, and Hetland and Hager [2005] expanded the solution to include irregular sequences. Actual fault systems exhibit irregular earthquake repeat times (and magnitudes). Changes in repeat interval for a single fault system and/or slip rates for a two fault system [Bennett et al., 2004] have been shown to have 

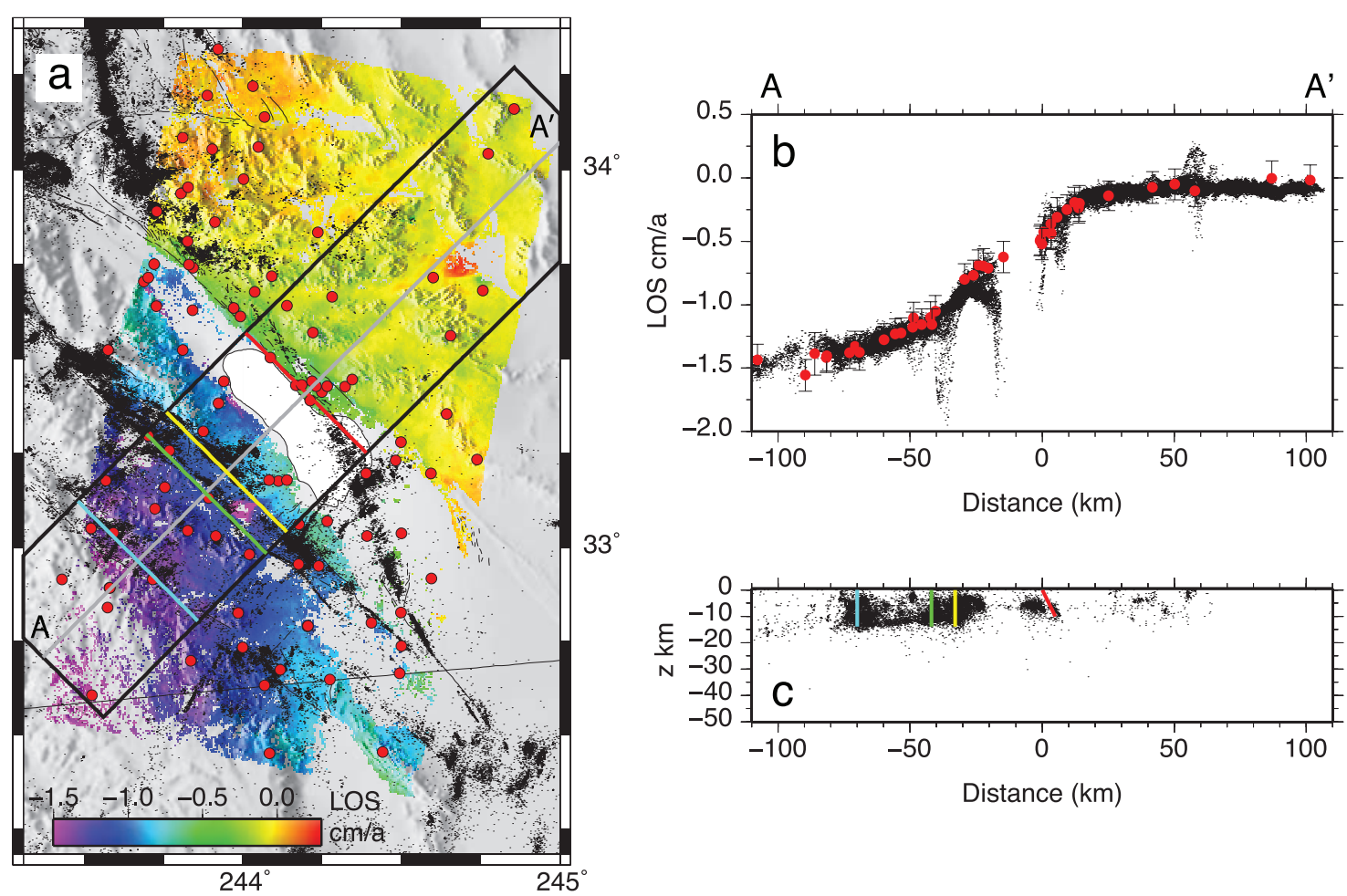

$33^{\circ}$

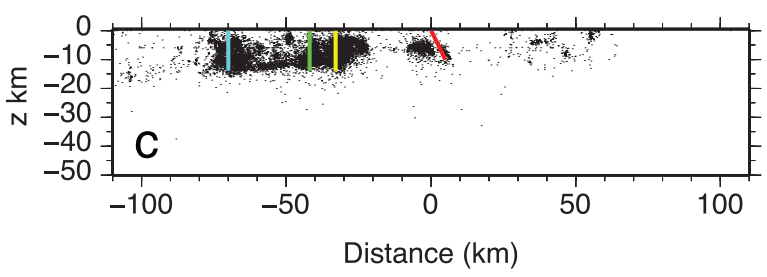

Figure 3. Data used in this study. (a) Shaded topographic relief map of the study area showing the mean InSAR line of sight velocities and the locations of the CMM3 geodetic sites (red dots) falling within the InSAR data area. Fine black dots are relocated seismicity from Lin et al. [2007]. Black rectangle outlines the data region used for the earthquake cycle analysis. Red line indicates the trace of the San Andreas fault, yellow line indicates the trace of the eastern branch of the San Jacinto fault, green line indicates the trace of the western branch of the San Jacinto fault, and cyan line indicates the trace of the Elsinore fault used in the finite element modeling. Gray line indicates the center of the profile and separates the north and south portions of the profile area. (b) InSAR (fine black dots) and CMM3 (large red dots with $1 \sigma$ error bars) data projected onto the central profile (CMM3 horizontal velocities have been projected into the satellite LOS on the basis of the actual LOS vector across the InSAR swath). (c) Projection of Lin et al. 's [2007] seismicity along the profile. Colored lines correspond to the fault traces in Figure $3 \mathrm{a}$ and show their modeled depths and dips.

significant effects on velocity profiles through residual stresses that retain a "memory" of the previous cycle state [Hetland and Hager, 2006; DiCaprio et al., 2008]. In our models we only consider linear (Maxwell) viscoelastic rheologies. This may be inappropriate in the lower crust and upper mantle if dislocation creep $(n \approx 3$; the stress exponent in the constitutive equation relating strain rate to stress) is dominant over diffusion creep $(n=1)$ over seismic cycle timescales [Bürgmann and Dresen, 2008]. Postseismic deformation within the first few years following the 1992 Landers and 1999 Hector Mine, California, earthquakes can be explained by power law, strain rate-dependent viscous flow in the upper mantle [Freed and Bürgmann, 2004; Freed et al., 2007]; this postseismic deformation might also be explained with recoverable transient viscoelastic rheologies [Pollitz et al., 2001]. As long as the background stresses are larger than the stress variations due to earthquakes, the interseismic velocities in models with power law viscosities are approximately similar to those predicted by models with Maxwell rheologies [Hetland et al., 2006], and except for the immediate postseismic period, interseismic velocities in models with recoverable transient viscoelastic rheologies are similar to those in models with Maxwell rheologies [Hetland and Hager, 2005]. Hence, by assuming only Maxwell viscosities, we implicitly assume that they approximate the effective viscosities over seismic cycle timescales. If the effective viscosities of the lithosphere vary significantly over the interseismic period, increasing from the postseismic period to the later interseismic times, then our inferred Maxwell viscosities will be biased [Thatcher and Pollitz, 2008]. Currently, earthquake cycle models with nonlinear rheologies are numerically intractable for the requirements of this study. Moreover, because of the lack of early postseismic deformation in this region, we do not consider non-Maxwell rheologies in this paper.

[16] By using finite element models, we can gain insight into the effects of either layered or laterally heterogeneous viscosity structure on the interseismic deformation (Figure 5). With a lateral variation in viscosity below the fault, the interseismic deformation varies less on the side of the fault above the high-viscosity region compared to above the low-viscosity region (Figure 5b) [Malservisi et al., 2001]. However, it is important to note that the interseismic velocities on either side of the fault are piecewise quite distinct from those for a 

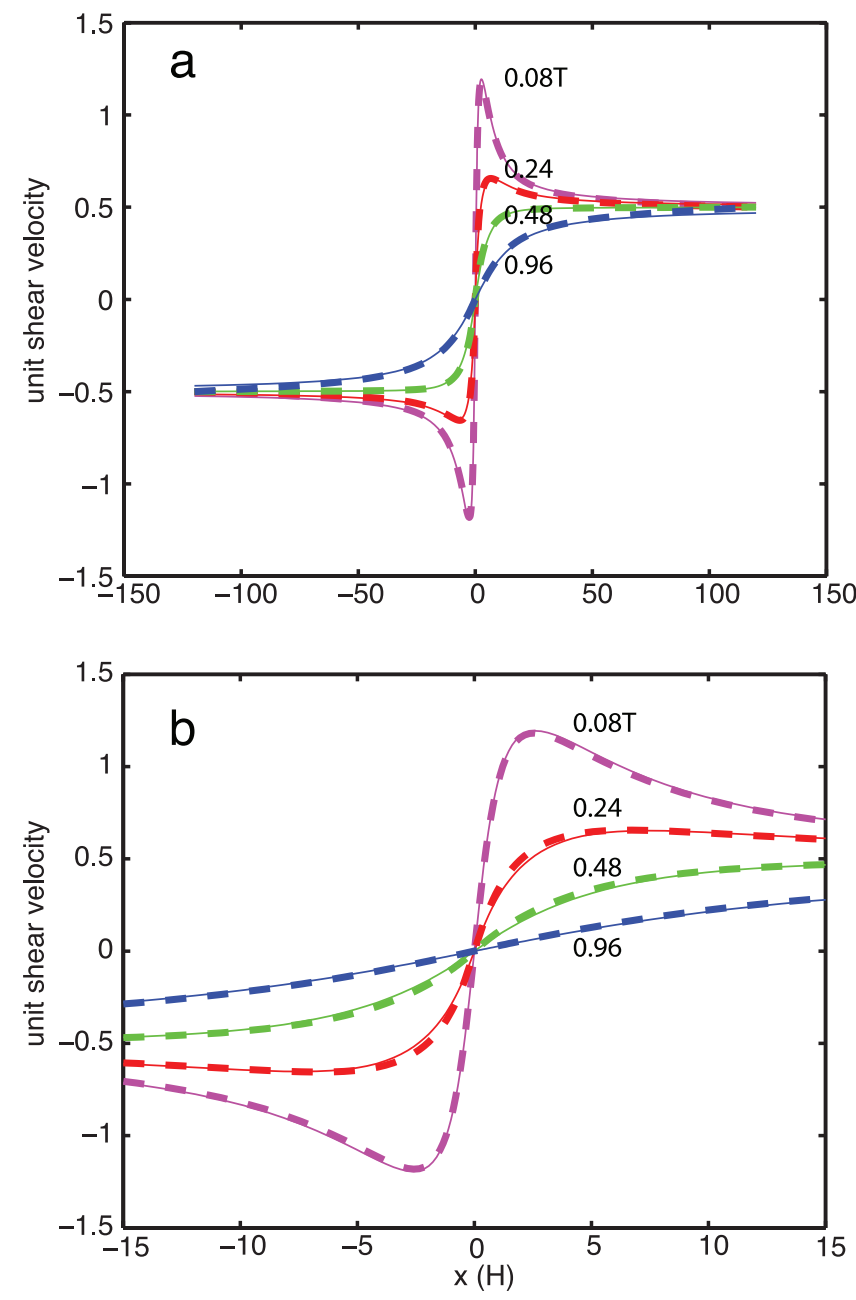

Figure 4. Earthquake cycle model velocities as a function of time into the cycle $(T)$ for a unit thickness elastic layer over a viscoelastic half-space (shear modulus is $30 \mathrm{GPa}$, viscosity is $1 \times 10^{19} \mathrm{~Pa} \mathrm{~s}$ ) cut by a strike-slip fault of unit width. Comparison of the FEM solution (dashed lines) with the analytic solution of Savage and Prescott [1978]. (a) Full solution out to the FEM driving width of \pm 120 fault widths $(H)$. (b) Zoom in of the nearer fault zone of \pm 15 locking depths, which is similar to the distance range examined in this study.

model with a homogeneous viscous lower region. For example, soon after an earthquake the postseismic velocities in the low-viscosity side are actually larger than in the homogeneous case. Additionally the location of zero velocity shifts relative to the fault trace through the interseismic period. The results we show in Figure 5b are for a rather large discontinuity in viscosity below the fault, whereas in this study, we only consider lateral viscosity variations in the lower crust under the Salton Trough. This more limited structural variation most likely results in fairly limited perturbations from models with no lateral variation in the lower crust. As we shall see in the subsequent sections, the sharpness of the geodetic velocity profile across the SAF is not well explained by a weaker lower crust to the west of the fault. In contrast, a layered structure is able to sufficiently describe both significant early cycle variations (equivalent to a low-viscosity half-space) and large strains across the faults late in the cycle (equivalent to a high-viscosity half-space; Figure 5a). Finally, we note that even though we do not consider other heterogeneous distributions of viscosity, since these earthquake cycle models depend on the Maxwell relaxation times, and we assume a heterogeneous elastic structure, there is a slight lateral and layered heterogeneity of relaxation times in all of these models.

\subsection{Model Setup}

[17] We model interseismic velocities using the finite element modeling (FEM) software GeoFEST v. 4.3 for the
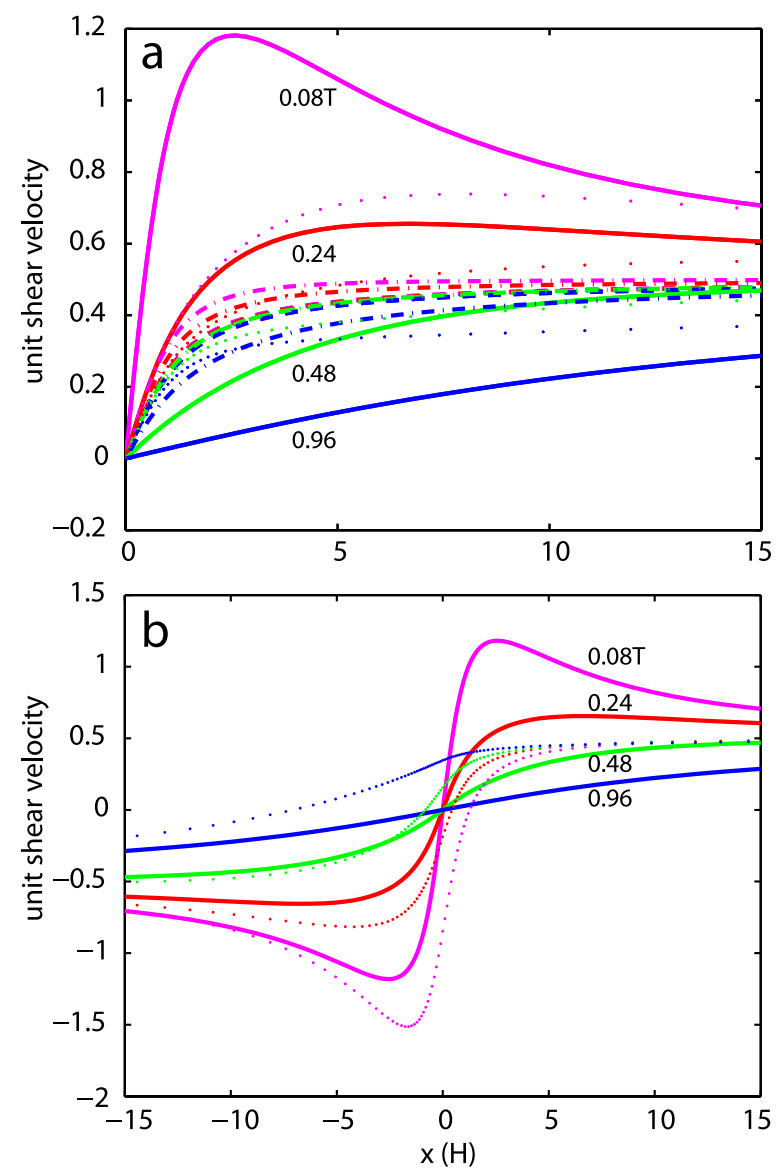

Figure 5. Comparison of different effects of viscosity and vertical (layered) and lateral viscosity variations on earthquake cycle profiles with unit $( \pm 0.5)$ far-field shear velocities at various times into the earthquake cycle $(T)$. Elastic layer is of unit thickness, and for the layered case, the lower crust extends from 1 to 3 elastic layer depths $(H)$. The strike-slip fault is located at $x=0$ and breaks the entire elastic layer. (a) Comparison between viscoelastic half-space solutions for $\eta=10^{19}$ (solid lines), $10^{20}$ (dashed-dotted lines), and $10^{21} \mathrm{~Pa} \mathrm{~s}$ (dashed lines), with a $10^{21} \mathrm{~Pa}$ s viscosity lower crust over a $10^{19} \mathrm{~Pa} \mathrm{~s}$ viscosity upper mantle (dotted lines). Plot shows only the positive $x$ half of the profiles out to 15 locking depths. (b) Comparison between the homogeneous viscosity (solid lines; $\eta=10^{19} \mathrm{~Pa} \mathrm{~s}$ ) half-space versus a laterally heterogeneous model (dotted lines) in which the half-space to the left ( $-x$ values) has a low viscosity $\left(10^{19} \mathrm{~Pa} \mathrm{~s}\right)$ and the half-space to the right ( $+x$ values) has a high viscosity $\left(10^{21} \mathrm{~Pa} \mathrm{~s}\right)$. 


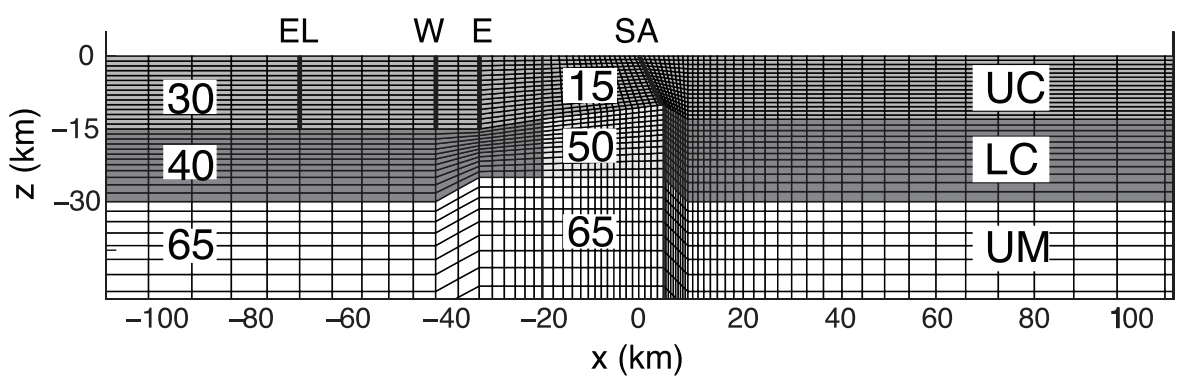

Figure 6. Close-up of the central portion of the finite element model mesh used in the SAF-SJF system analysis. Entire FEM extends from $\pm 1200 \mathrm{~km}$ away from the SAF and to $z=-1200 \mathrm{~km}$. Modeled faults are given by thick lines beneath the Elsinore (EL), western (W) and eastern (E) San Jacinto, and the San Andreas (SA) faults. Two properties differentiate each model structural domain: shear modulus and viscosity. The upper crust (UC), lower crust (LC), and upper mantle (UM), each have shear moduli of 30, 40, and $65 \mathrm{GPa}$, respectively, as indicated on the left. Beneath the Salton Trough (defined by the medium thickness lines, $x=-20$, and the SA fault and its deeper extension) the shear modulus for the UC, LC, and $\mathrm{UM}$ are as indicated (in GPa). Different gray scale shading shows the viscosity groups used in the modeling. The UC is shown by medium gray shading (purely elastic); the LC consists of two viscosity domains, the region outside of (dark gray) and beneath (light gray) the Salton Trough; and the UM has uniform viscosity (white).

2-D mesh shown in Figure 6. We assume a heterogeneous shear modulus distribution on the basis of the SVM3 seismic velocity model [Kohler et al., 2003; Fay and Humphreys, 2005]. Figure 4 shows a comparison between the analytic solution of Savage and Prescott [1978] and the FEM solution for unit elastic layer thickness $H$, a lower homogeneous viscosity of $10^{19} \mathrm{~Pa} \mathrm{~s}$, and a homogeneous shear modulus of $3 \times 10^{10} \mathrm{~Pa}$. For modeling the southern San Andreas fault system, we use a finite element mesh consisting of three layers: an upper elastic crust overlying a viscoelastic lower crust, which in turn, is underlain by a viscoelastic upper mantle. The depth to the bottom of the upper crust is set to $15 \mathrm{~km}$ west of the SJF and tapers linearly to the lower extension of the SAF at a depth of $10 \mathrm{~km}$, which then tapers to $13 \mathrm{~km}$ depth to the east of the SAF. This upper crust depth variation is similar to that used by Fay and Humphreys [2005] in their earthquake cycle modeling, is based on the seismic tomography model of Lin et al. [2007], and is comparable to the seismogenic depths estimated for these fault segments [Nazareth and Hauksson, 2004]. Except in the region between the SJF and SAF faults, the depth to the Moho (lower crust-upper mantle boundary) is set to $30 \mathrm{~km}$ on the basis of the Moho depths of Yan and Clayton [2007].

[18] The fault locations are based on the relocated seismicity of Lin et al. [2007]. For the San Jacinto fault we divide it into two strands, the western one coinciding with the Coyote Creek fault, and the eastern one following the seismicity lying along the Clark and Superstition hills faults. For the San Andreas fault we use the location and strike defined at the center of the profile shown in Figure 3. In the cross section of relocated seismicity [Lin et al., 2007] we see that within our profile area the San Andreas fault appears to have a $60^{\circ}$ dip to the NE, as suggested by Fialko [2006], although this is most evident in the northern portion of the profile, becoming more diffuse toward the south. We also include the Elsinore fault in these models, even though it lies toward the SW edge of our data and is expected to have a slip rate of around $5 \mathrm{~mm} / \mathrm{a}$ or less [Magistrale and Rockwell, 1996].
[19] The entire model domain extends $\pm 1200 \mathrm{~km}$ horizontally from the center of the mesh (taken to be the surface trace of the San Andreas fault) and vertically from the Earth's surface to a depth of $1200 \mathrm{~km}$. The model is edge driven at a constant velocity orthogonal to the plane of the mesh, and we assume periodic earthquakes for each fault. Note that in these models there is no imposed shear on the extensions of the fault at depth, rather we consider each fault to extend only to the bottom of the upper crust. These earthquake cycle models require many (100s) earthquake cycles to "spin up," such that the interseismic velocities no longer depend on the fault loading conditions or the number of previous ruptures (i.e., cycle invariant velocities) [Hetland and Hager, 2006]. The number of cycles required depends on the highest viscosity in the model, whereas the time step required in the finite element solution depends on the lowest viscosity in the model.

[20] These models require an assumed earthquake repeat time for each fault. Estimates for southern San Andreas fault (SSAF) (south of Cajon Pass) repeat times vary with location and time span (Figure 1). The recurrence time at Cajon Creek, at the northernmost end of the SSAF is estimated at 150-200 years, over the past $14 \mathrm{ka}$ [Weldon and Sieh, 1985], although paleoseismology slightly farther to the SE at Plunge Creek suggests that this northernmost segment may experience more frequent large events compared to sites farther south [McGill et al., 2002]. The Mission Creek strand of the SAF at Thousand Palms has an estimated mean interval of 215 years over the past 1200 years, with the last major event occurring in the late 1600s [Fumal et al., 2002]. Closer to the location of this study the SSAF at Mecca hills has been estimated at 260 years over the past $34 \mathrm{ka}$ [Shifflett et al., 2002]. With the same paleoseismology estimates available as used by Fay and Humphreys [2005], we use their repeat interval of 250 years for the SSAF.

[21] The repeat time for large earthquakes along the San Jacinto fault (SJF) is less well sampled. The only estimate applicable to this study is the $\sim 260$ year repeat time estimated by Rockwell et al. [2003] that formed the basis for the 
250 year repeat interval used by Fay and Humphreys [2005] and used in our modeling.

[22] The Elsinore fault's repeat time is estimated at 550600 years for the Temecula segment immediately to the north of our study cross section [Vaughan et al., 1999] to less than 200 years further north along the Glen Ivy segment [see Parsons, 2008, and references therein]. For our modeling we use a value of 500 years, although no data was found for the Coyote Mountain segment covered by the GPS and InSAR data used in our modeling. The low slip rate expected for the Elsinore fault $(<5 \mathrm{~mm} / \mathrm{a})$, along with its location at the $\mathrm{SW}$ edge of the data region, reduces the model sensitivity to this value. An alternate repeat time of 250 years was also tried and the difference in modeled slip rates were between 0.1 and $0.3 \mathrm{~mm} / \mathrm{a}$, with no change in preferred viscosity values.

[23] These earthquake cycle models give the interseismic velocities throughout the seismic cycle, and geodetic velocities are relatively instantaneous velocities compared to the interseismic period. Hence, to compare predicted velocities to the observed, we need to assume a time since the last rupture of each of the faults. When we know the time of the last fault rupture, we assume that time. When we do not know this information, we explore a variety of times into the earthquake cycle.

[24] We form Greens functions by calculating the cycle invariant velocities for each fault model and rheologic structure using unit fault slip rates and an assumed rupture period. The total solution is then obtained by linearly adding the individual solutions, appropriately rescaled by the fault slip rates. Note that this Greens function approach is possible since we only use linear rheologies, and we only combine individual solutions that used a common geometric and rheologic structure. Using this approach, we can invert for the best fault slip rates for each of the geometric and rheologic structures, and time since the last rupture on each fault.

\subsection{Modeling Results}

[25] The finite element modeling approach we use in this study allows for easy inclusion of lateral and vertical material properties and layer thicknesses, both of which we need to consider for the SSAF system. Lateral variations in the depth to the upper-lower crust and lower crust-upper mantle (Moho) transitions are found from seismological studies [Lin et al., 2007; Yan and Clayton, 2007], and changes in material properties beneath the Salton Trough must be considered given the tectonic setting and high heat flow [Magistrale, 2002; Fay and Humphreys, 2005; Fialko, 2006]. The main weakness of this method for earthquake cycle modeling is that it is computer intensive in the calculation of each fault's Greens function for a given set of material (and potentially structural) parameters, and does not afford itself to approaches that allow for a more complete exploration of the parameter space [Johnson and Segall, 2004; Hilley et al., 2005; Johnson et al., 2007].

[26] We generate Greens functions for all combinations of viscosities $\left(\eta=1,2.5,5,10,50,100 \times 10^{19} \mathrm{~Pa} \mathrm{~s}\right)$ in the material domains shown in Figure 6, with the constraint that the lower crustal viscosity beneath the Salton Trough must be less than or equal to the adjacent lower crust viscosity. We chose this constraint because the higher heat flow across the Salton Trough [Magistrale, 2002], more than likely translates to a weaker lower crust. Since these models are sensitive to the relaxation time $\left(\tau_{m}=\eta / \mu\right)$, there is a trade off between the viscosity and the shear modulus, and seismological studies suggest that shear modulus under the Salton Trough is higher than in the adjacent lower crust [Kohler et al., 2003; Lin et al., 2007].

[27] For a given set of times into the earthquake cycle of each fault (i.e., Elsinore, Coyote Creek, Clark, San Andreas) we find the best-fitting slip rates for each of the 126 rheologic structures. We select the structural model with the smallest chi-square $\left(\chi^{2}\right)$ divided by the number of data points $(\sim 33,000)$ minus the number of faults $(\sim 4)$. Since the standard deviations of the CMM3 velocities projected into the radar LOS are similar in magnitude $(\sim 1-2 \mathrm{~mm} / \mathrm{a})$ to those of the InSAR data, weighting the data becomes critical for a combined solution. In all of the cases presented here we deweight the InSAR data by a factor of 2000 , which we found to balance the contributions of the GPS and InSAR data to the $\chi^{2}$ of the solution misfit. Keeping the weighting value at one (essentially InSAR only solution) or infinite (essentially GPS only solution), does lead to small differences in the inferred slip rates and/or rheology, but they are not significant and appear to reflect either the cruder spatial sampling of the GPS or potential biases in the InSAR LOS that may be associated with imprecise deramping or locally strong vertical deformation. The latter does not affect the solution significantly, but does contribute large values to the misfit over all ranges of models. In all of these cases we consider the Elsinore and San Andreas faults to be late in their cycle (0.9), and consider a set of early, middle, and late cycle times for the western (Coyote Creek) and eastern (Clark) strands of the San Jacinto fault system. We then use the best-fitting rheologic structure to further explore the time since the last rupture of the two SJF strands.

\subsubsection{Full Profile}

[28] The best-fitting viscosity structure for the weighted inversion has a high-viscosity $\left(1 \times 10^{21} \mathrm{~Pa}\right.$ s $)$ lower crust over a lower-viscosity $\left(1 \times 10^{19} \mathrm{~Pa}\right.$ s $)$ upper mantle. Over the course of development of our finite element models (from the simplest to more realistic meshes, and from two to all four faults) the best-fitting models have consistently had a highviscosity $\left(1 \times 10^{21} \mathrm{~Pa} \mathrm{~s}\right)$ lower crust overlying a significantly lower-viscosity $\left(1 \times 10^{19} \mathrm{~Pa} \mathrm{~s}\right)$ upper mantle.

[29] To refine the best-fitting solution for the full width profile (Figure 3), we compute solutions for the best-fitting viscosity structure over the full range of times into the earthquake cycle $(d T)$ for both strands of the San Jacinto fault system (Coyote Creek fault to the west, Clark fault to the east). Plots of the misfit (Figure 7 (top)), inferred east strand slip rate (Figure 7 (middle)) and west strand slip rate (Figure 7 (bottom)) are shown in Figure 7. The lowest misfit values lie where either one or both strands are early in their cycle, and the minimum is when $d T=0.3$ for both strands. There is a broad minimum in the misfit surface, and either of the SJF strands could be late in their cycle, but not both. Generally, the slip rates of the two strands trade-off as their respective $d T$ 's change. Within the low-misfit region where $d T$ is small for the western strand, as $d T$ increases for the eastern strand, the eastern strand's slip rate decreases and the western strand's increases. Likewise for low $d T$ for the eastern strand, as $d T$ of the western strand increases, the eastern (western) slip rate increases (decreases). For all combinations of $d T$ for the two strands, the total slip of the SJF remains about $24-26 \mathrm{~mm} / \mathrm{a}$. 

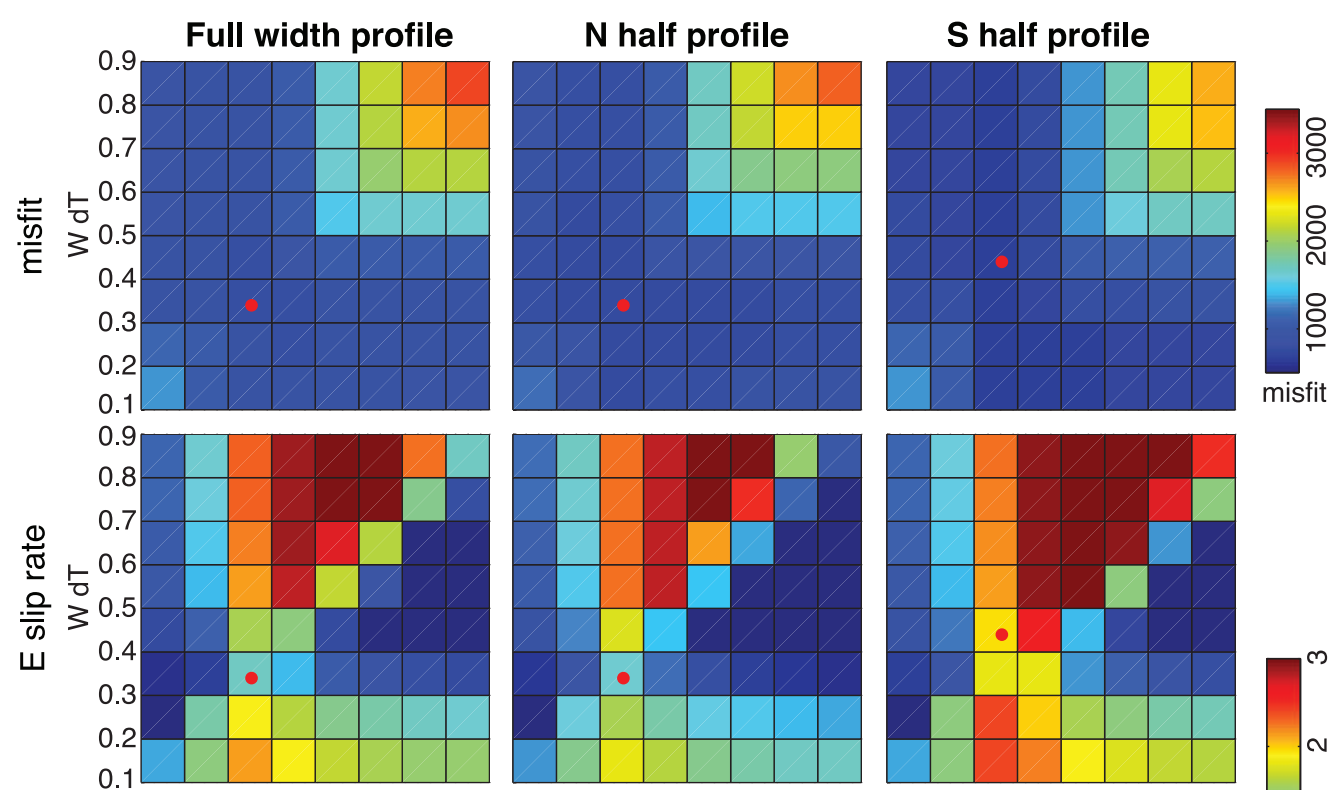

misfit
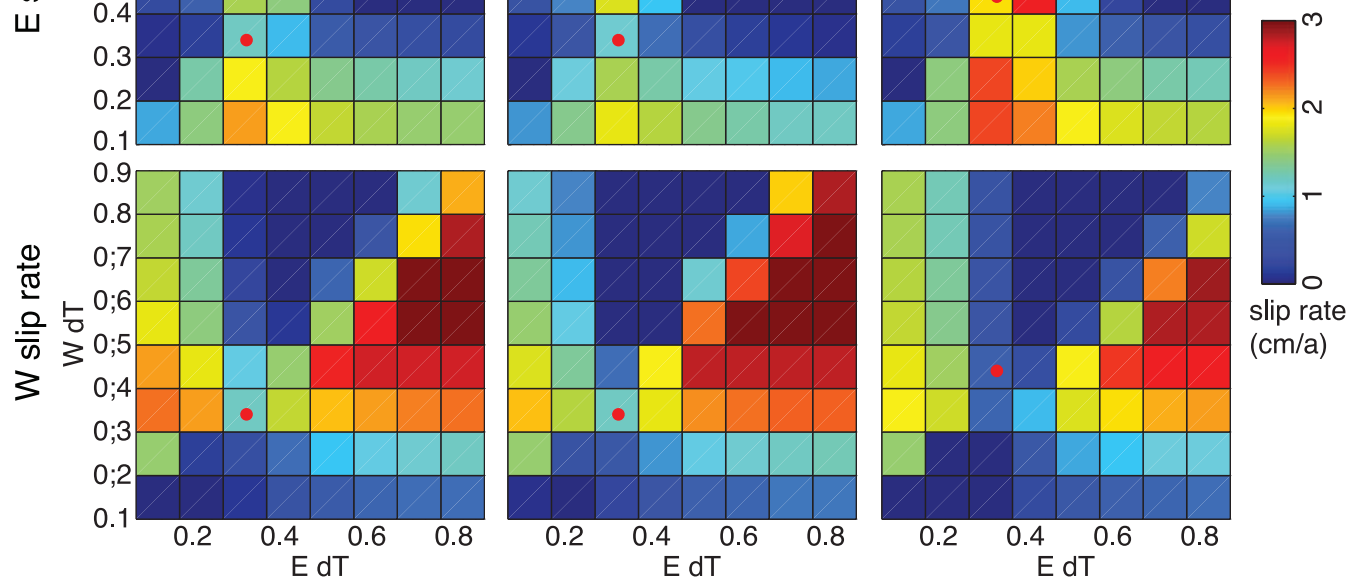

Figure 7. Grid search over values of $d T$ from 0.1 to 0.9 for the western and eastern branches of the San Jacinto fault (Elsinore and San Andreas faults set to $d T=0.9$ ) for the Full, North, and South profiles. (top) Misfit for each profile, (middle) $\mathrm{E}$ slip rate as a function of $\mathrm{E}$ and $\mathrm{W} d T$, and (bottom) $\mathrm{W}$ slip rate as a function of $\mathrm{E}$ and $\mathrm{W} d T$. Red dot in each indicates the minimum error $\mathrm{E}$ and $\mathrm{W} d T$ combination for that profile.

[30] For the best-fitting $d T$ ( 0.3 for both SJF branches) we show the effects of assumed viscosity for the lower crust and upper mantle on the inferred fault slip rates. For each of these models Figure 8 shows the misfit and the resulting estimated slip rates for the Elsinore, summed SJF, and SAF. The minimum solution (Model 31) has a nearly equally low misfit with that of Model 25, whose only difference is a slightly lower viscosity of $5 \times 10^{20} \mathrm{~Pa} \mathrm{~s}$ (but still a long relaxation time compared to the earthquake cycle length).

[31] To compute the best-fitting solution and slip rate uncertainties, we compute slip rate solutions for 1000 perturbations of the data on the basis of the random Gaussian uncertainties of each data point. Figure 9 shows the best-fitting solution and the associated slip rates. We find slip rates of $2 \pm 3,12 \pm 9$, $12 \pm 9$, and $17 \pm 3 \mathrm{~mm} / \mathrm{a}$ for the Elsinore, Coyote Creek, Clark, and San Andreas faults, respectively.

\subsubsection{North-South Profiles}

[32] The relative slip rates of the two strands of the SJF system, and possible subsurface connection with the Superstition hills fault, has been a matter of debate. Fialko [2006] considered the eastern fault to best fit the InSAR and CMM3 data. Visual inspection of the northern and southern halves of the profile used in the previous modeling shows an apparent difference in the curvature of each, with the northern profile appearing to have less concentrations of strain rate above the San Jacinto fault compared to the southern profile (i.e., less of an inflection point in the interseismic velocities; Figure 10). Some variations in the LOS velocities are expected because of the changing viewing angle of the SAR LOS across the swath. There is also the question of whether the most recent significant earthquakes (1968 Borrego Mountain, 1987 Superstition hills) lying within or adjacent to each subprofile have a residual postseismic effect on the geodetic data.

[33] To understand whether there are discernable alongstrike variations in both the preferred $d T$ and slip rates, we repeat the grid search for the best-fitting $d T$ for each strand of the SJF and resultant slip rates for each subprofile (Figure 7). We maintain the same best-fitting rheology structure as for the full width profile. We also maintain the same weighting factor for the InSAR data. The model solutions for each profile are shown in Figure 10. Indeed, the best-fit slip rates of the two subprofiles indicate that the slip rate of the western (eastern) strand decreases (increases) to the south, although the total slip rate on the two strands is the same within the model uncertainties. For the north profile we see that the solution is only slightly different from the solution for the entire profile. A slight increase in Elsinore slip rate is offset by decreases in eastern SJF and SAF slip rates. For the southern 

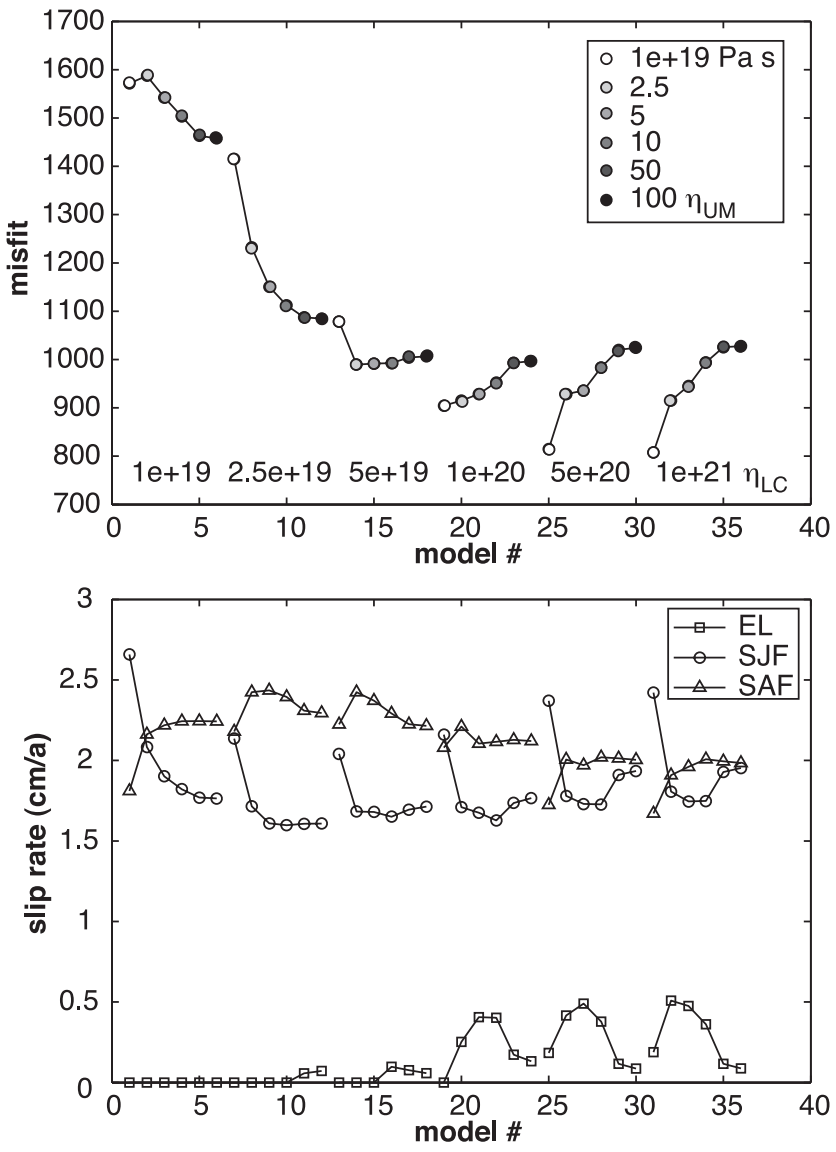

Figure 8. Comparison of (top) model misfit versus viscosity structure and (bottom) estimated slip rates for the best-fitting model ( $d T$ 's, data deweighting factor) shown in Figure 9a, corresponding to Model 31 above. The models are arranged in groups of six where the Upper Mantle viscosity cycles through the range from $1 \times 10^{19}$ to $1 \times 10^{21} \mathrm{~Pa}$ s (see legend) over a given lower crust viscosity (horizontal labels beneath their respective model group). EL, Elsinore fault; SJF, the sum of both San Jacinto fault branches; SAF, San Andreas fault.

profile the best-fitting time into the earthquake cycle is essentially the same ( 0.4 versus 0.3 for the western SJF). However, from north to south there is a $50 \%$ reduction in the slip rate for the western SJF, a reduction to zero for the Elsinore, and a slight change for the SAF. This slip is transferred to the eastern SJF with a slip rate approaching $20 \mathrm{~mm} / \mathrm{a}$.

\section{Discussion}

[34] The objectives of this study are to use available point geodetic and InSAR secular velocities to constrain fault slip rates, and the crust and upper mantle rheologies across the southern San Andreas fault system. Recent studies by Fay and Humphreys [2005] and Fialko [2006] have raised questions regarding lateral heterogeneity (in shear modulus structure), the dip of the San Andreas fault (away from vertical), and the location of the current active strand of the San Jacinto fault system.

\subsection{Lateral and Layered Viscosity Structure}

[35] Lateral contrasts in rheology beneath the Salton Trough are likely to be transitional from continental to oceanic spread- ing on the basis of its tectonic setting, heat flow, and seismic velocities [Lachenbruch et al., 1985; Magistrale, 2002; Lin et al., 2007], and were considered for models of geodetic profiles across the SSAF [Fay and Humphreys, 2005; Fialko, 2006]. Layered crust and upper mantle rheology is important for understanding Earth material properties and geodetic data provide sensitivity to this to varying degrees on the basis of the timescales and processes observed [Bürgmann and Dresen, 2008; Thatcher and Pollitz, 2008], with earthquake cycle models providing some constraints on lower crust and upper mantle rheologies.

\subsubsection{Salton Trough Lower Crust}

[36] In this study, we did not consider lateral variations of viscosity between the Peninsular Ranges and Pacific plate lithosphere to the SW of the Elsinore fault, nor within the North American plate interior NE of the San Andreas fault. Additionally, we did not consider finer variations in rheology within the lower crust and upper mantle as would be expected for realistic mineral assemblages and geotherms [Bürgmann and Dresen, 2008; Thatcher and Pollitz, 2008].

[37] Models in which the lower crust beneath the Salton Trough has a lower viscosity compared to the adjacent lower crust, predict interseismic velocities too relaxed late in the cycle compared to models with laterally homogeneous lower crust viscosities. We did not test models in which the Salton Trough viscosity is greater than the adjacent crust, although it is unlikely that the decrease in $\mu$ could be exactly compensated by increases in $\eta$. A higher viscosity would be inconsistent with the high heat flow values over the Salton Trough [Lachenbruch et al., 1985; Magistrale, 2002], that tend to suggest higher temperatures and lower viscosity at depth. However, it may be that sufficient material heterogeneity can increase (or maintain) viscosity despite increased temperatures [Thatcher and Pollitz, 2008]. This latter explanation was proposed by Lachenbruch et al. [1985] to explain the neutral elevation across the Salton Trough in terms of an isostatic balance between upper crustal sediments and a gabbroic lower crust, and might be due to intrusion or underplating from the mantle during extension. This hypothesis is supported by seismically inferred velocity anomalies in the lower crust of this region [Lin et al., 2007].

\subsubsection{Lower Crust and Upper Mantle Structure}

[38] The rheologic structure required in our models contains a high-viscosity $\left(10^{21} \mathrm{~Pa}\right.$ s) lower crust (LC) over a lower-viscosity upper mantle (UM), either at the minimum viscosity allowed in our analysis, $1 \times 10^{19} \mathrm{~Pa} \mathrm{~s}$, or the next lowest, $2.5 \times 10^{19} \mathrm{~Pa}$ s. This result is similar to that of Fay and Humphreys [2005], though slightly outside both their upper and lower bounds. The reason for this strong over weak structure is illustrated in Figure 5a, with the high- $\eta$ lower crust required to maintain the strong velocity gradient near the SAF, and the low- $\eta$ upper mantle allowing sufficient early postseismic response to best fit the slightly heightened San Jacinto early to midcycle velocity gradients.

[39] The observed high heat flow values within the Salton Trough (see section 4.1.1) and Basin and Range province to the north suggest that lower crust composition within this region is likely to be gabbroic [Lachenbruch et al., 1985], and dry, to achieve the relative LC to UM strength contrast that our models imply [Afonso and Ranalli, 2004]. This model is at odds with the jelly sandwich model for mature continental lithosphere, which is characterized by a strong uppermost 


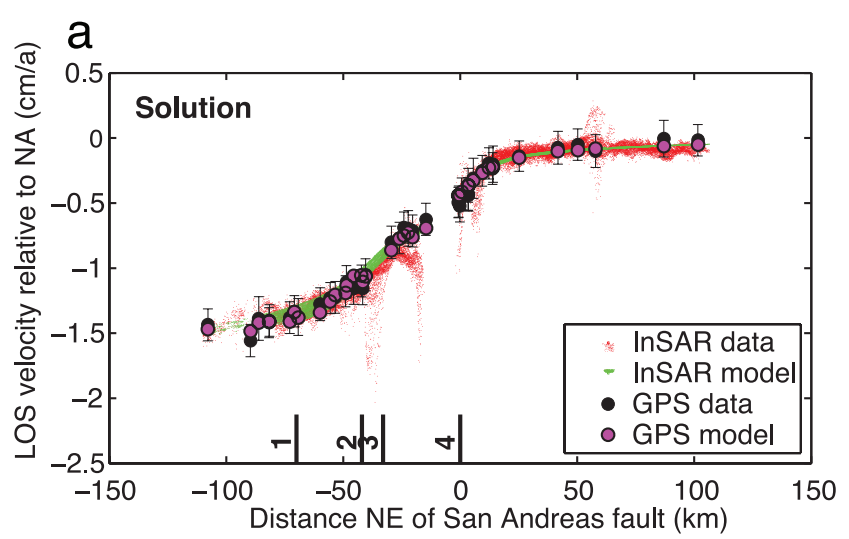

b
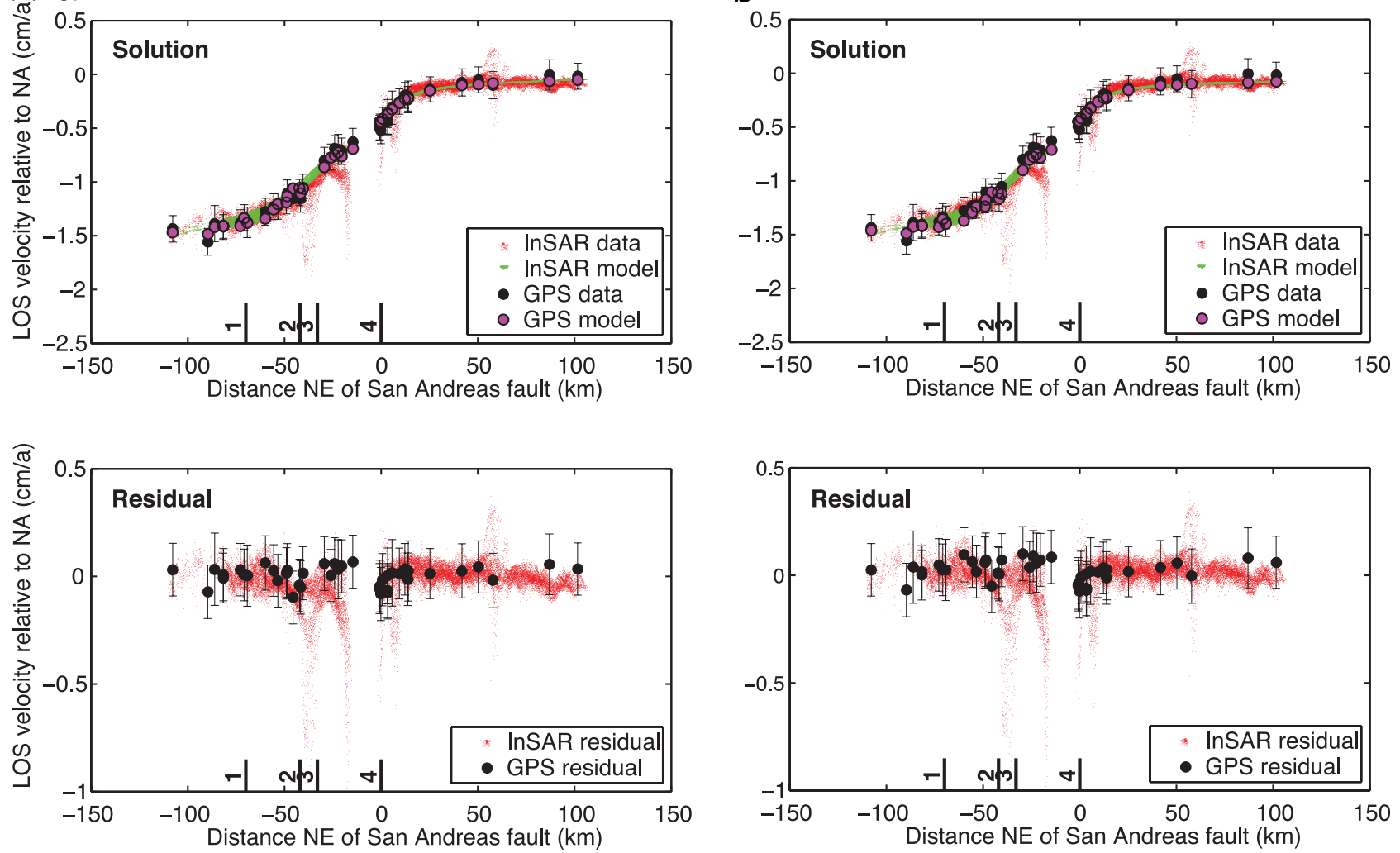

misfit: 808 InSAR sfactor: 2000

T: 500250250250

dT: $\begin{array}{llll}0.9 & 0.3 & 0.3 & 0.9\end{array}$

v: $0.19 \pm 0.31 \quad 1.21 \pm 0.90 \quad 1.21 \pm 0.94 \quad 1.67 \pm 0.25$

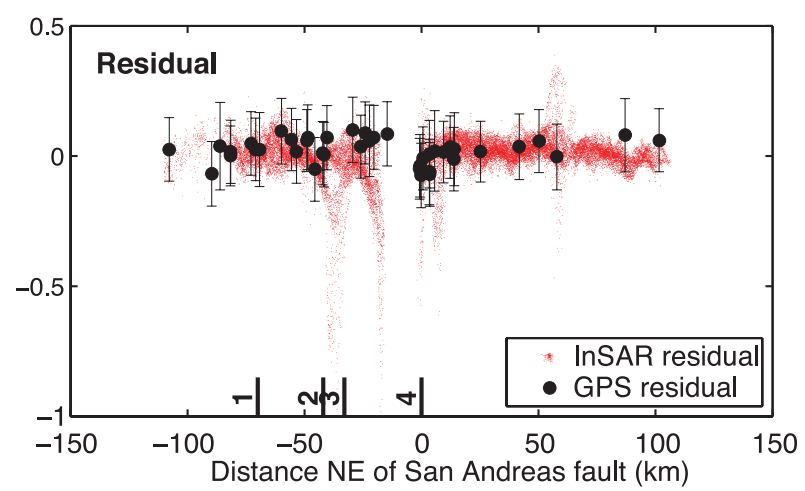

misfit: 206 InSAR sfactor: 1.00

T: 500250250250

dT: $\begin{array}{llll}0.9 & 0.1 & 0.5 & 0.9\end{array}$

v: $0.00 \pm 0.0 \quad 0.48 \pm 0.0 \quad 2.00 \pm 0.0 \quad 1.80 \pm 0.0$

Figure 9. (a) Modeled versus observed velocities across the SAF, SJF, and Elsinore fault system for the best-fitting rheology structure $\left(\eta_{\mathrm{LC}}=10^{21} \mathrm{~Pa} \mathrm{~s}\right.$ and $\left.\eta_{\mathrm{UM}}=10^{19} \mathrm{~Pa} \mathrm{~s}\right)$ for the 126 rheology combinations (Greens functions) considered and an InSAR deweighting factor of 2000. (b) Is the same as in Figure 9a but for unit weighting. For each solution, (top) shows the model versus data fits and (bottom) shows the residual (note different velocity scale), with the locations of the Elsinore, western SJF, eastern SJF, and San Andreas faults given by the lines numbered 1,2,3, and 4, respectively. Below these plots are the misfit (useful for comparing like-weighted solutions), the deweighting InSAR factor, $T$ (years) is the length of the earthquake cycle for each fault (in order 1-4), $d T$ is the time (fraction of $T$ ) into the earthquake cycle for each fault, $v(\mathrm{~cm} / \mathrm{a})$ gives each fault's estimated slip rate and its uncertainty from 1000 solution runs (see main text for explanation).

mantle relative to the lower crust [Burov and Watts, 2006], but is in line with the crème brûlée model [Jackson, 2002] for a wet, and therefore weak, upper mantle [Karato, 1986]. A wet upper mantle has been argued for the Basin and Range and SW United States [Dixon et al., 2004] on the basis of lava and mantle xenolith geochemical data. Similar low-viscosity upper mantle has been argued in the region on the basis of loading of Lake Mead [Kaufmann and Amelung, 2000; Cavalié et al., 2007].

\subsection{Fault Slip Rates}

[40] Perhaps the most surprising result from our models is the consistently high partitioning of slip on the San Jacinto fault system $(24-26 \mathrm{~mm} / \mathrm{a})$ relative to the San Andreas fault $(16-19 \mathrm{~mm} / \mathrm{a})$. In contrast, block models of southern California based on GPS velocities find slip rates of 9-15 and $23-26 \mathrm{~mm} / \mathrm{a}$ on the SJF and SAF, respectively [Bennett et al., 1996; Meade and Hager, 2005; Becker et al., 2005].
Fialko [2006] found SJF and SAF slip rates of 19-21 and 22-28 mm/a, respectively, while Fay and Humphreys [2005] found SJF and SAF slip rates of $14-15$ and $22-23 \mathrm{~mm} / \mathrm{a}$, respectively. While paleoseismic and dating of fault offset landforms often provide a range of possible slip rates, and may justify one or more of these geodetic analyses, the differences in geodetic data used and/or modeling approaches are at the heart of these different inferred slip rates. We examine in more detail the model-based geodetic interpretations and the field-based geologic observations in the following subsections (Table 1).

\subsubsection{Geodetic Model Differences}

[41] As mentioned in the beginning of this paper, interpretations of geodetic data are, by their very nature, model dependent. The classic approach, has been to consider the surface velocities across a strike-slip fault to be due to steady creep on the semi-infinite deep extension of the fault, resulting in the classic "arctan" function velocity profile for the 

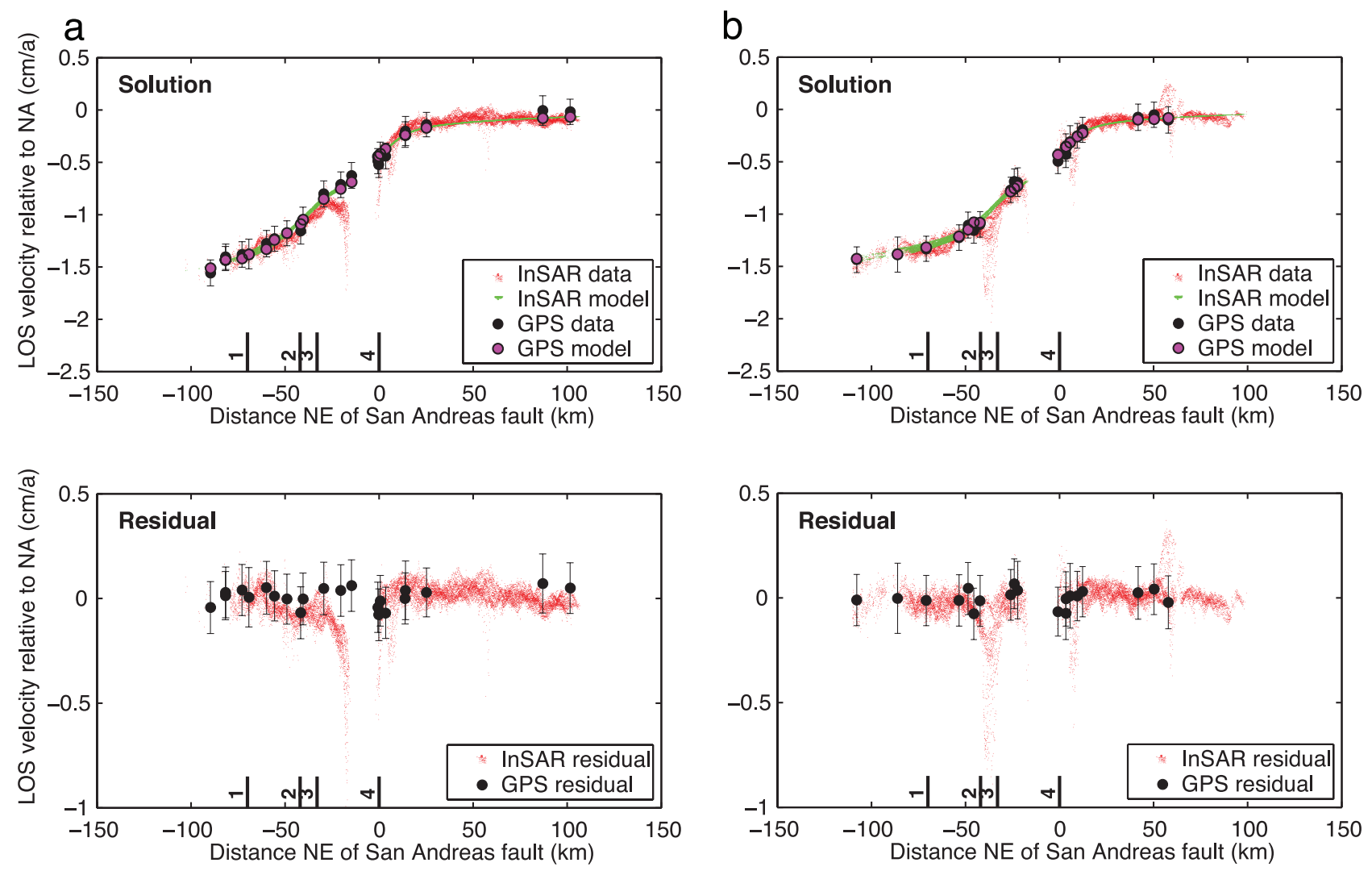

misfit: 735 InSAR sfactor: 2000

T: 500250250250

dT: $\begin{array}{llll}0.9 & 0.3 & 0.3 & 0.9\end{array}$

v: $0.49 \pm 0.46 \quad 1.20 \pm 0.99 \quad 1.15 \pm 1.03 \quad 1.58 \pm 0.31$

misfit: 655 InSAR sfactor: 2000

T: 500250250250

dT: $\begin{array}{llll}0.9 & 0.4 & 0.3 & 0.9\end{array}$

v: $0.00 \pm 0.26 \quad 0.59 \pm 0.88 \quad 1.95 \pm 0.87 \quad 1.61 \pm 0.32$

Figure 10. Same as in Figure 9, but for the (a) North and (b) South profiles.

interseismic velocities [e.g., Savage and Burford, 1973]. Instead of calculating the velocities due to the deep fault creep, most researchers rely on an equivalent representation, and calculate the deformation due to the locked portion of the fault sliding steadily backward during the interseismic period. The interseismic velocities are then those due to this "back slip" plus block-like offsets across the fault [Savage and Burford, 1973]. The appeal of this approach is its computational speed, and can be readily extended to 3-D fault systems [e.g., Meade and Hager, 2005]. This approach is sufficient in the absence of geologic or geophysical information requiring more complex models. The back slip approach was at the basis of Fialko's [2006] analysis and formed the initial step of Fay and Humphreys's [2005] analysis through a finite element model that allowed variations from the homogeneous elastic half-space. A fundamental assumption of the half-space solution of Savage and Burford [1973] is that the interseismic velocities are steady and do not depend on the time in the earthquake cycle. This is because Savage and Burford's [1973] model is equivalent to a model with the fault in the elastic layer overlying a Maxwell viscoelastic halfspace, driven by far-field shear and with $\tau_{m}>T$ [e.g., Hetland and Hager, 2006].

[42] Depending on the rheologic structure of the lithosphere and the time since the last earthquake, Savage and Burford's [1973] backslip model may result in a quite different inferred slip rate for a measured velocity profile [e.g., Hetland and
Hager, 2006]. Fay and Humphreys [2005] found around 15 and $21 \mathrm{~mm} / \mathrm{a}$ for the SJF and SAF, respectively, using the elastic model, and $\sim 14$ and $23 \mathrm{~mm} / \mathrm{a}$ using the earthquake cycle approach. With respect to geodetic observations suggesting more equal slip partitioning between these faults [Johnson et al., 1994; Anderson et al., 2003], Fay and Humphreys [2005] suggest that postseismic effects from the 1968 Borrego Mountain earthquake could bias results in favor of a higher SJF rate. This is particularly pertinent since they consider a larger area along strike than we do, and an earthquake spanning one segment of their modeled system can represent a substantial deviation from the 2-D approximation they use.

[43] The difference between the viscoelastic earthquake cycle model of Fay and Humphreys [2005] and ours appears more puzzling. Aside from small differences in the layered structure and the dipping SAF in our model, the following are two important areas where our models differ:

[44] 1. Most seriously is that rather than using truly farfield shear to drive their models, they assume that because they see no long-term crustal strain beyond $65 \mathrm{~km}$ distance in either direction from the midpoint between the SAF and SJF traces, they drive their model by imposing that the crust beyond this distance moves uniformly at the plate rate. Additionally, they argue that models with broader shear zone widths distribute strain too broadly to match the geodetic data. 

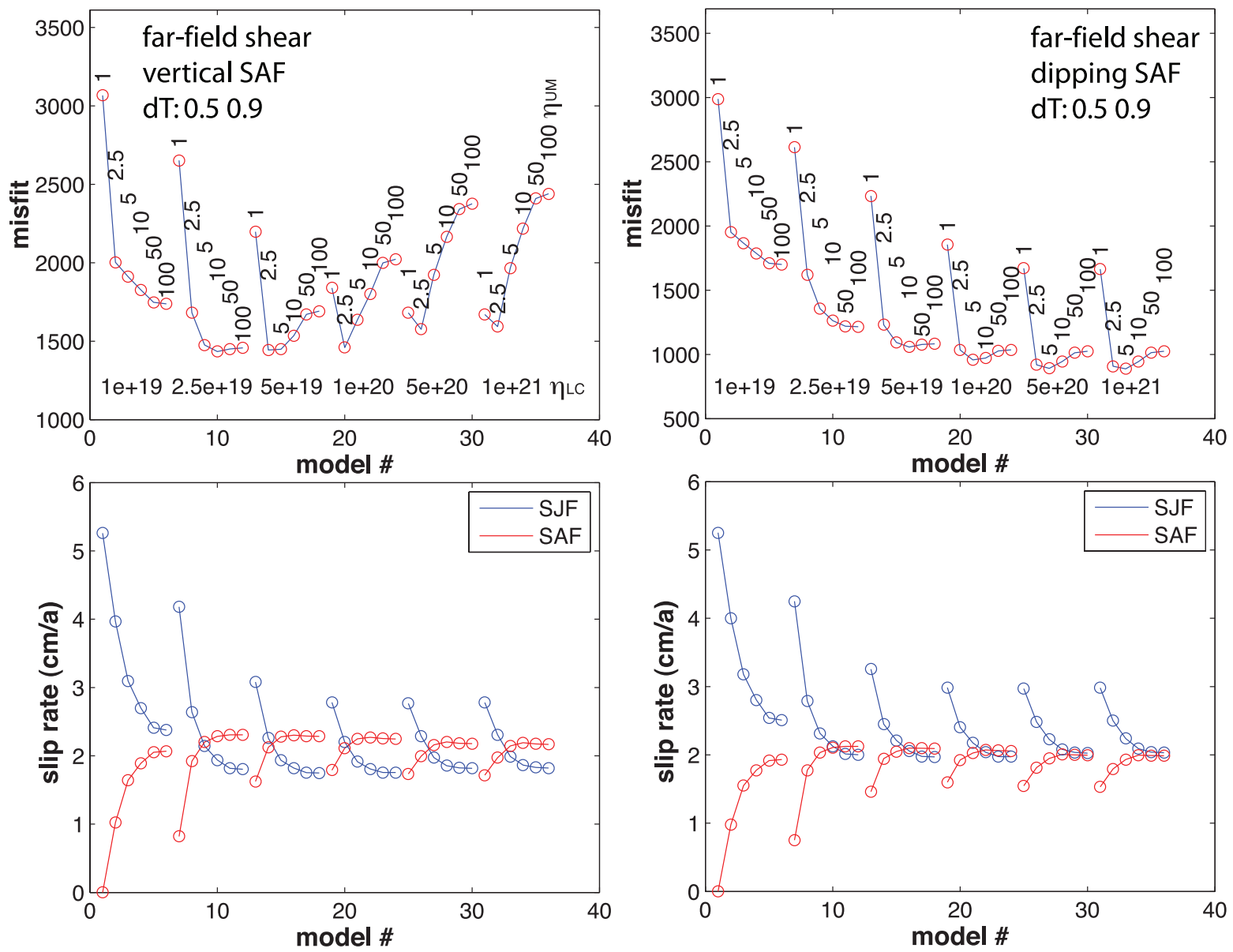

Figure 11. Far-field shear comparison of (top) model misfit versus viscosity structure and (bottom) estimated slip rates for a single SJF at $42 \mathrm{~km}$ from an either (left) vertical or (right) dipping SAF. The models are arranged in groups of six where the Upper Mantle viscosity cycles through the range from $1 \times 10^{19}$ to $1 \times 10^{21} \mathrm{~Pa} \mathrm{~s}$ (vertical labels) over a given lower crust viscosity (horizontal labels beneath their respective model group). Note the change in misfit axis values between vertical SAF and dipping SAF.

[45] 2. Instead of exploring a range of upper mantle viscosities, they fix an upper mantle viscosity of $5 \times 10^{19} \mathrm{~Pa} \mathrm{~s}$, and they only consider lower crust viscosities from $2.5 \times$ $10^{19}$ to $10^{20} \mathrm{~Pa}$ s. The shear zone width limitation has a potentially significant effect. Present-day studies of postseismic deformation following the Landers and Hector Mine earthquakes in the Mojave Desert just north of our study area illustrate that postseismic (i.e., early earthquake cycle) strain extends to distances of hundreds of kilometers from the faults [Freed et al., 2007]. The effect on interseismic velocities of forcing the far-field shear velocities at distances of 4-5 locking depths $(60-75 \mathrm{~km})$ is quite drastic, even in the higher viscosity $\left(\eta>10^{20} \mathrm{~Pa} \mathrm{~s}\right)$ cases (Figure 5). Such a restriction would most likely bias inferred slip rates and would affect the estimated time into the earthquake cycle (i.e., see comparisons given by Pollitz [2001]). The effect by Fay and Humphreys [2005] of limiting the range of viscosities could also account for some of the rate discrepancies. For example, when we solved for the best-fitting rheology structure for the full width profile at early $d T$ for both SJF strands, we found that $\eta_{\mathrm{LC}}=10^{20} \mathrm{~Pa}$ s with a total SJF rate of $\sim 15$ and a SAF rate of $\sim 23 \mathrm{~mm} / \mathrm{a}$ fit the geodetic velocities best. These results are similar to those of Fay and Humphreys's [2005] slip rate estimates.
[46] To demonstrate the effects of limiting the shear zone width, a vertical versus dipping SAF, and the effects of rheology we generate a set of models over 36 combinations of lower crust and upper mantle viscosities. We consider our far-field driven $( \pm 1200 \mathrm{~km})$ model (Figures 11 and 13) and a narrow shear zone $( \pm 65 \mathrm{~km})$ model similar to Fay and Humphreys's [2005] FEM model (Figures 12 and 13 ). We use a single SJF strand (Coyote Creek fault) located $42 \mathrm{~km}$ from an either vertical or dipping SAF. These results show that the dipping SAF significantly reduces the model misfit, which is evident in Figure 13 where we see that it better fits the velocity gradient observed across the fault (see section 4.3 for additional discussion on the dipping SAF). In addition, models with a dipping SAF favor a stronger lower crust compared to those with a vertical SAF. Comparing the narrow shear zone (SZ) models (Figure 12) with the far-field shear (FF) models (Figure 11) for a vertical SAF we see that the SZ model for the ranges of viscosities given by Fay and Humphreys [2005] (UM is $5 \times 10^{19} \mathrm{~Pa}$ s and LC is $2.5-10 \times$ $10^{19} \mathrm{~Pa} \mathrm{~s}$ ) produce slip rates for the SJF and SAF around 15 and $25 \mathrm{~mm} / \mathrm{a}$, respectively, consistent with their results, whereas the FF model produces more equitable slip rates. For the dipping SAF the SJF rates increase at the expense of the SAF rate for both the SZ and FF models. The SZ model 

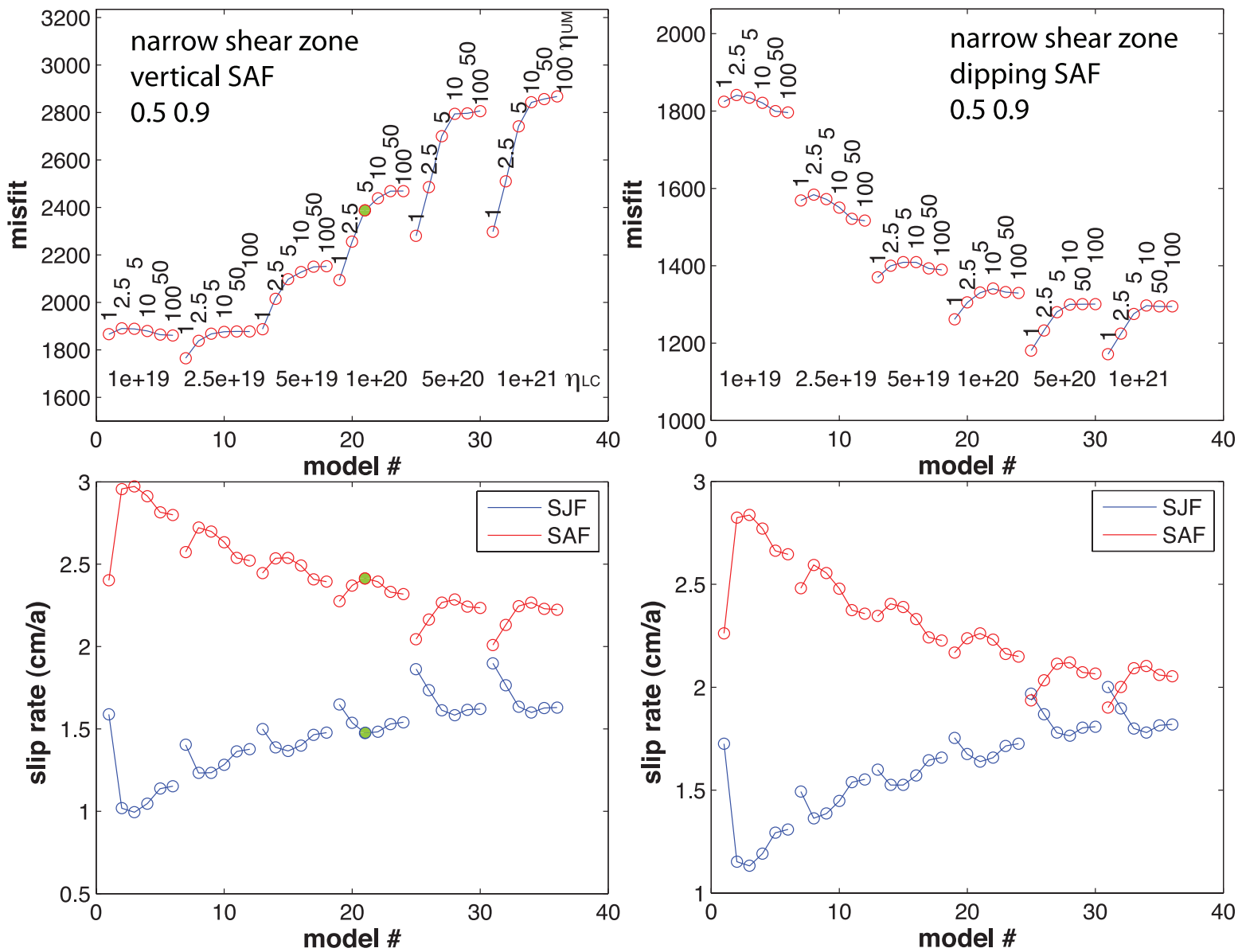

Figure 12. Narrow shear zone comparison of (top) model misfit versus viscosity structure and (bottom) estimated slip rates for a single SJF at $42 \mathrm{~km}$ from an either (left) vertical or (right) dipping SAF. The models are arranged in groups of six where the Upper Mantle viscosity cycles through the range from $1 \times 10^{19}$ to $1 \times 10^{21} \mathrm{~Pa} \mathrm{~s}$ (vertical labels) over a given lower crust viscosity (horizontal labels beneath their respective model group). Note the change in misfit axis values between vertical SAF and dipping SAF. Shear zone width is $130 \mathrm{~km}$ and is centered $20 \mathrm{~km}$ to the SW perpendicular to the SAF to approximate Fay and Humpreys's [2005] model. Green filled circle at Model 21 corresponds approximately to the "best-fitting" viscosity structure used by Fay and Humphreys [2005].

consistently has a higher misfit value, due in large part to its requirement that the model be at zero velocity within $65 \mathrm{~km}$ to the NW of the SAF, and therefore offset from the data.

[47] Fialko [2006] using a deep slip-driven elastic model, found SAF slip rates of $25 \mathrm{~mm} / \mathrm{a}$ and SJF rates of either $21 \mathrm{~mm} / \mathrm{a}$ for strong lateral shear modulus heterogeneity and a vertical SAF, or $19 \mathrm{~mm} / \mathrm{a}$ with no shear modulus heterogeneity, a dipping SAF, and the active strand of the SJF shifted to the east (on the Clark fault). In this case both models have higher SAF slip rates than either Fay and Humphreys [2005] or inferred in this study. One difference between the Fialko [2006] model and ours is that he considers variations in locking depth, whereas we fix the elastic layer thickness and assume the faults are locked throughout the entire elastic layer. Fialko [2006] found a $12 \mathrm{~km}$ locking depth was preferable in both his models. When we assumed that the upper crust in the area of the SJF was $13 \mathrm{~km}$, we inferred negligible differences in the solution compared to those we inferred with a $15 \mathrm{~km}$ upper crust. The most significant difference between our study and that of Fialko [2006] is that he did not consider rheologies that would cause time-dependent velocities.

[48] These modeling differences illustrate the effects of either narrow shear zone width or (similarly) elastic rheology in resulting in lower SJF rate estimates. It is also apparent that trade-offs in slip rate with rheology can result in significant variations from a very high $(\sim 24 \mathrm{~mm} / \mathrm{a}) \mathrm{SJF}$ combined rate to one in which the SJF-SAF rates are both around $20 \mathrm{~mm} / \mathrm{a}$ (Figures 8 and 11).

\subsubsection{Geologic Rate Estimates}

[49] Estimates of fault slip rates based on geologic field measurements of geomorphic features depend on location, technique, and age of the features [see Petersen and Wesnousky, 1994] (Figure 1). The differences between the SAF and SJF slip rates integrated over various times has been postulated to reflect a feedback mechanism that produces longer term variations in slip rates between these faults [Bennett et al., 2004]. Here we summarize the published slip rate estimates for the southern SAF and SJF systems (Table 1). 

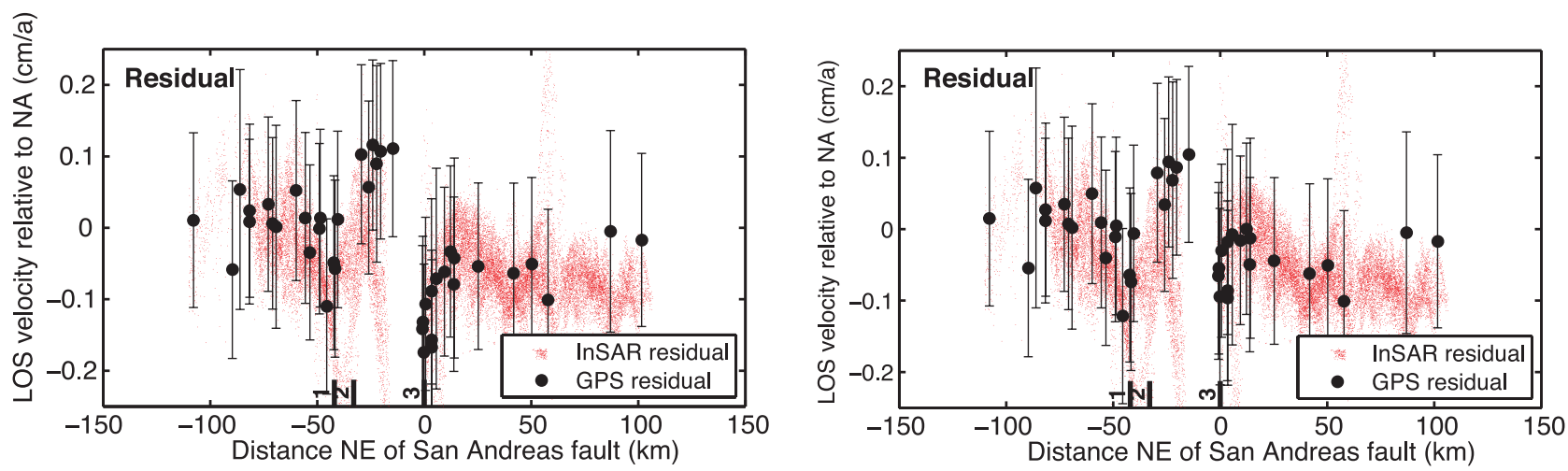

misfit: 2388 InSAR sfactor: 2000

T: 250250

dT: $0.5 \quad 0.9$

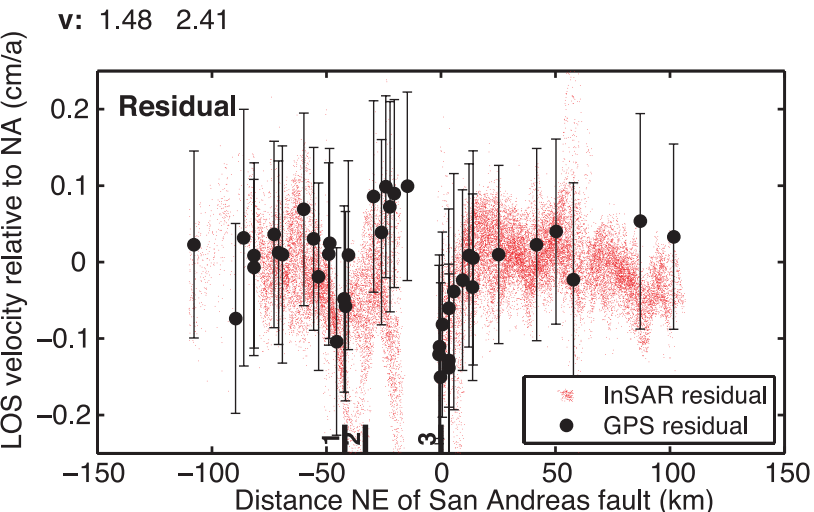

misfit: 1330 InSAR sfactor: 2000

T: 250250

dT: $0.5 \quad 0.9$

v: 1.642 .26

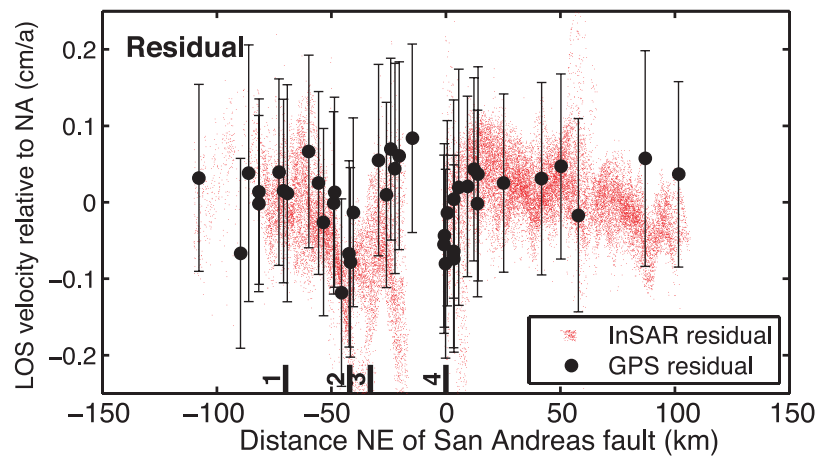

misfit: 1636 InSAR sfactor: 2000

T: 250250

dT: $0.5 \quad 0.9$

v: 1.912 .25

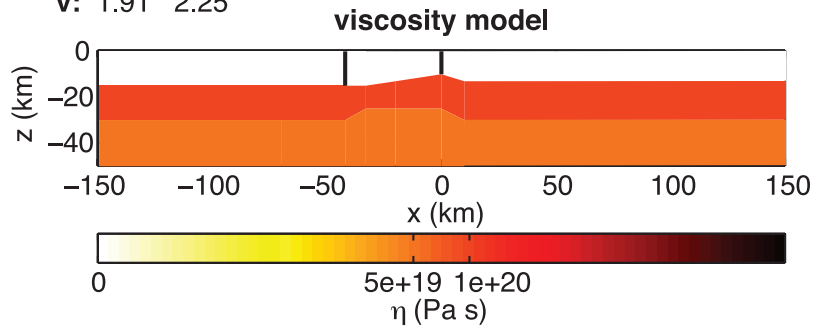

misfit: 958 InSAR sfactor: 2000

T: 250250

dT: $0.5 \quad 0.9$

v: $2.18 \quad 2.03$

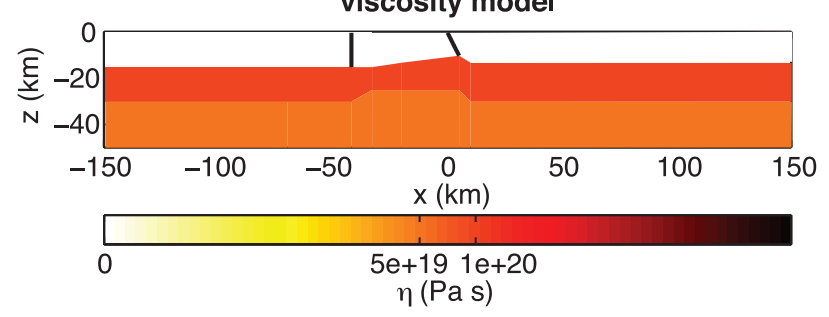

Figure 13. Comparison of the Model 21 residuals (observed minus synthetic LOS velocities) for (top) the narrow shear zone model to (middle) the far-field shear model for the (left) vertical SAF and (right) $60^{\circ}$ dipping SAF. The estimated rates for the SJF and SAF correspond to those in Figures 11 and 12. (bottom) Viscosity and fault structures for the (left) vertical SAF and (right) dipping SAF are shown.

[50] The southern SAF has generally been considered to have a slip rate around $25 \mathrm{~mm} / \mathrm{a}$. Holocene estimates in Cajon Pass [Weldon and Sieh, 1985], at the extreme northern end of the SSAF, give values of $\sim 25 \mathrm{~mm} / \mathrm{a}$. More relevant to our analysis are rates south of the Banning Pass. At Indio Sieh [1986] found a minimum rate of $30 \mathrm{~mm} / \mathrm{a}$ for the $1000-$ 1700 AD time period, at the high end of the $10-35 \mathrm{~mm} / \mathrm{a}$ interpreted at the nearby Biskra Palms site by Keller et al. [1982]. Recently the estimate of Keller et al. [1982] has been reevaluated at the Biskra Palms site by van der Woerd et al. [2006] on the basis of revised alluvial fan displacement offsets and more accurate dating methods to give a SSAF rate of $\sim 16 \mathrm{~mm} / \mathrm{a}$, within the range of Keller et al. [1982]. This suggests that the current best estimate of slip on the
$\mathrm{SSAF}$ is $\sim 16 \mathrm{~mm} / \mathrm{a}$, with even slower rates near Indio and the Salton Sea farther south reflecting shallower creep [Sieh and Williams, 1990; Shifflett et al., 2002].

[51] The SJF slip rate is generally considered to be around $10 \mathrm{~mm} / \mathrm{a}$ on the basis of the Quaternary slip rates estimated at Anza of 9-13 mm/a [Rockwell et al., 1990], which are comparable to the late Pleistocene estimate of $8-12 \mathrm{~mm} / \mathrm{a}$ at the same location [Sharp, 1981]. Some recent studies have found evidence for higher slip rates. Recent Anza work by Rockwell et al. [2006] estimates a rate greater than $16 \mathrm{~mm} / \mathrm{a}$. North of Anza Kendrick et al. [2002] estimated Quaternary slip rates greater than $20 \mathrm{~mm} / \mathrm{a}$ along the northern section of the SJF. South of Anza, which is the portion of the SJF more relevant to this study, both the geology and the geologic slip 
rate estimates are more complex. Here the SJF splits into two main branches (though this too is an oversimplification), the Coyote Creek fault on the west, and the Clark fault, with its apparent continuation beneath thick surface sediments to the Superstition hills fault, to the east. Dorsey [2002] estimated an $\sim 10 \mathrm{~mm} / \mathrm{a}$ Quaternary slip rate for the Coyote Creek fault, consistent with the idea that this branch of the SJF is the main active trace of the SJF, and the location of the 1968 Borrego Mountain earthquake [Heaton and Helmberger, 1977]. Recent estimates for the Clark fault suggest a lifetime slip rate of $\sim 14 \mathrm{~mm} / \mathrm{a}$ [Belgarde and Janecke, 2007]. In contrast, estimates from Quaternary offsets along the Clark and Coyote Creek faults give mid-Holocene combined rates of 5-11 mm/a [Le and Oskin, 2007], supporting the idea that complementary slip variations over time occur between the southern SAF and SJF faults [Bennett et al., 2004].

[52] The emerging picture for the southern SAF and the SJF is one that has a lower rate on the SAF $(\sim 16 \mathrm{~mm} / \mathrm{a}) \mathrm{com}-$ pared to earlier estimates on the basis of improved techniques, but one that still has a significant variation for the SJF. For the SJF, the results of Kendrick et al. [2002], Rockwell et al. [2006], Dorsey [2002], and Belgarde and Janecke [2007], suggest that total slip rates are in the range of $16-24 \mathrm{~mm} / \mathrm{a}$ across the SJF system, giving a more coherent high slip estimate than in previous studies. These rates are fairly consistent with those we have inferred.

\subsection{SAF Dip and SJF Active Branch}

[53] The questions of whether the SAF is nonvertical and whether the Clark fault accommodates significant slip within the SJF system are largely motivated by the study of Fialko [2006]. We do find in our finite element models that a dipping SAF produces a better fit to the velocity profile (see section 4.2.1). Over the full range of viscosity models tested in this study the $60^{\circ}$ dipping SAF always better matched the steep gradient across the SAF than did the $90^{\circ}$ dipping models. Furthermore, the profile in the seismicity across the northern portion of our cross section shows an apparent dip to the seismicity between 5 and $10 \mathrm{~km}$ depth and is offset to the NE from the SAF trace [Lin et al., 2007]. There is also evidence over nearly the entire length of the SAF in southern California for significant dip to the fault [Fuis et al., 2007]. The FE models we ran showed that the vertical SAF produces a steeper gradient than a dipping one, but with a shift to the SW (negative fault perpendicular direction in our case) relative to models for a dipping fault. This spatial shift leads to a worse fit for the vertical SAF model to the data near the fault than for the dipping model. Given the seismological evidence in favor of a NE dipping SAF, in this study we prefer a model with the SAF dip of $60^{\circ}$ to the east.

[54] Similarly, the question of the active branch of the SJF lying beneath the Clark-Superstition Hills trace is more contentious. South of the Santa Rosa mountains no clear evidence exists for structural continuity between the Clark and Superstition Hills faults in a region of soft deforming sediments in the Borrego Badlands [Lutz et al., 2006; Kirby et al., 2007]. This is also an area that has relatively low seismicity [Nazareth and Hauksson, 2004; Lin et al., 2007]. Fialko [2006] preferred a model in which the entire strain accumulation on the SJF fault system was resolved on the most recently active eastern strand, and is consistent with the partitioning of the slip rates in the SJF system we found when equally weighting the InSAR and GPS data (Figure 9b). Likewise, the large uncertainty associated with our SJF rates reflects the significant trade-offs between the two faults' slip rates due to their close proximity in conjunction with tradeoffs in assumed $d T$ into the current earthquake cycle.

\subsection{Possible 3-D Effects}

[55] Two-dimensional viscoelastic models imply an infinite along-strike dimension, and thus ignore along-strike variations in rheologic structure or the finite length of ruptures. The relatively low spread of the interseismic velocities along the fault trace in this region, argues that we may approximate this system with 2-D models. Indeed the success of 2-D models to describe the geodetic data is a strong argument in support of the use of 2-D models [e.g., Fay and Humphreys, 2005; Fialko, 2006]. Additionally, 3-D elastic block models do not show strong along-strike variations in fault slip rates to the north of the Salton Trough region [Bennett et al., 1996; Meade and Hager, 2005; Becker et al., 2005]. However, it is important to note that these block models, while allowing for possible along-strike variations in slip rates, neglect heterogeneities in rheologies. Two-dimensional models allow for exploration of lateral variations of rheologies normal to the fault traces, but they assume that there is no along strike variation in rheology. In this region, it is plausible that lower crustal rheology may vary from the Salton Trough to the north. Along strike variations in lower crust and upper mantle viscosity may be quite important to this system, with an increasing viscosity to the north limiting along strike flow under the Salton Trough, and thus countering the impact of a weaker lower crust under the Salton Trough.

[56] The relatively good fits to the geodetic profile across the SAF-SJF systems that we achieved over a fairly broad range of viscoelastic earthquake cycle model parameters suggest how 3-D perturbations to the velocity profiles could affect conclusions on the basis of 2-D models. This is borne out by observations showing the spatial extent of the postLanders and Hector Mine earthquake's deformation [Freed et al., 2007] and arguments for perturbations in the CMM3 geodetic velocities adjacent the rupture of the 1968 Borrego Mountain earthquake [Fay and Humphreys, 2005]. The trade-offs in parameter space between $d T$, slip rate, and rheology that we demonstrated in our 2-D models might be "absorbing" poorly modeled 3-D lateral effects from earthquakes that occurred outside the model area and variations in rheology along the strike of the SAF-SJF systems.

\section{Conclusions}

[57] We explore 2-D viscoelastic earthquake cycle models, and constrain fault slip rates for assumed crustal structures using ERS InSAR and CMM3 point geodetic velocities across the Salton Sea portion of the San Andreas-San Jacinto fault system. We use a heterogeneous shear modulus model on the basis of the CVM3 velocity model [Kohler et al., 2003], and assume an elastic upper crust overlying a Maxwell viscoelastic lower crust and mantle. To fit the strong velocity gradients across the faults, and accounting for the different times since the last earthquakes on each of the faults, we require a high-viscosity $\left(10^{21} \mathrm{~Pa} \mathrm{~s}\right)$ lower crust and a lowerviscosity $\left(10^{19} \mathrm{~Pa} \mathrm{~s}\right)$ upper mantle. We estimate slip rates for 
the Elsinore, western San Jacinto (Coyote Creek), eastern San Jacinto (Clark-Superstition hills), and San Andreas faults. Our best-fitting full profile model gives slip rates of $2 \pm 3,12 \pm 9,12 \pm 9$, and $17 \pm 3 \mathrm{~mm} / \mathrm{a}$ for the Elsinore, Coyote Creek, Clark, and San Andreas faults, respectively. In our preferred model both branches of the SJF are best fit with each fault at $30 \%$ into the current earthquake cycle, implying significant residual postseismic effects from the 1968 Borrego Mountain and 1987 Superstition hills earthquakes are contained in the present-day geodetic data. Apparent along-strike variations in the velocity profiles between the northern and southern halves of the study area suggest possible variations in along-strike slip rates. Modeling these two subregions separately we find an apparent decrease/ increase in W/E San Jacinto slip rates from north to south (Elsinore 5 to 3; western SJF 12 to 6; eastern SJF 12 to 20; SAF steady at $16 \mathrm{~mm} / \mathrm{a})$, but this is well within the uncertainties and not significantly different from the full profile solution.

[58] Acknowledgments. We thank the European Space Agency for ERS data provided through the WInSAR archive. CMM3 data were provided through the Southern California Earthquake Center. Maps and profiles in this paper were generated using the public domain Generic Mapping Tools (GMT) software [Wessel and Smith, 1995]. We greatly appreciate thorough and insightful reviews by Noah Fay, one anonymous reviewer, and associate editor Tim Dixon. E.A.H. thanks the Tectonics Observatory and the Seismological Laboratory, Caltech, for postdoctoral support. This research was carried out at the Jet Propulsion Laboratory, California Institute of Technology, under a contract with the National Aeronautics and Space Administration and funded through the internal Research and Technology Development program.

\section{References}

Afonso, J. C., and G. Ranalli (2004), Crustal and mantle strengths in continental lithosphere: Is the jelly sandwich model obsolete?, Tectonophysics, 394, 221-232, doi:10.1016/j.tecto.2004.08.006.

Anderson, G., D. C. Agnew, and H. O. Johnson (2003), Salton Trough regional deformation estimated from combined trilateration and surveymode GPS data, Bull. Seismol. Soc. Am., 93, 2402-2414, doi:10.1785/ 0120030014.

Argus, D. F., M. B. Heflin, G. Peltzer, F. Crampe, and F. H. Webb (2005), Interseismic strain accumulation and anthropogenic motion in metropolitan Los Angeles, J. Geophys. Res., 110, B04401, doi:10.1029/2003JB002934

Becker, T. W., J. L. Hardebeck, and G. Anderson (2005), Constraints on fault slip rates of the southern California plate boundary from GPS velocity and stress inversions, Geophys. J. Int., 160, 634-650, doi:10.1111/ j.1365-246X.2004.02528.x.

Belgarde, B., and S. U. Janecke (2007), A "hidden" fault? Structural geology of three segments of the Clark fault, San Jacinto fault zone, California, Geol. Soc. Am. Abstr. Programs, 39(6), 375.

Bennett, R. A., W. Rodi, and R. E. Reilinger (1996), Global Positioning System constraints on fault slip rates in southern California and northern Baja, Mexico, J. Geophys. Res., 101, 21,943-21,960, doi:10.1029/ 96JB02488.

Bennett, R. A., A. M. Friedrich, and K. P. Furlong (2004), Codependent histories of the San Andreas and San Jacinto fault zones from inversion of fault displacement rates, Geology, 32(11), 961-964, doi:10.1130/ G20806.1.

Berardino, P., R. Lanari, and E. Sansosti (2002), A new algorithm for surface deformation monitoring based on small baseline differential SAR interferograms, IEEE Trans. Geosci. Remote Sens., 40(11), 2375-2383, doi:10.1109/TGRS.2002.803792.

Bürgmann, R., and G. Dresen (2008), Rheology of the lower crust and upper mantle from rock mechanics, geodesy, and field observations, Annu. Rev. Earth Planet. Sci., 36, 531-567, doi:10.1146/annurev.earth.36.031207.124326.

Burov, E. B., and A. B. Watts (2006), The long-term strength of continental lithosphere: "Jelly sandwich" or "crème brûlée"?, GSA Today, 16, 4-10, doi:10.1130/1052-5173(2006)016<4:TLTSOC $>2.0$.CO;2.

Cavalié, O., M.-P. Doin, C. Lasserre, and P. Briole (2007), Ground motion measurement in the Lake Mead area, Nevada, by differential synthetic aperture radar interferometry time series analysis: Probing the lithosphere rheological structure, J. Geophys. Res., 112, B03403, doi:10.1029/ 2006JB004344

Chen, C. W., and H. A. Zebker (2001), Two-dimensional phase unwrapping with use of statistical models for cost functions in non-linear optimization, J. Opt. Soc. Am., 18, 338-351, doi:10.1364/JOSAA.18.000338.

DeMets, C. (1995), A reappraisal of seafloor spreading lineations in the Gulf of California: Implications for the transfer of Baja California to the Pacific plate and estimates of Pacific-North America motion, Geophys. Res. Lett., 22, 3545-3548, doi:10.1029/95GL03323.

DeMets, C., and T. H. Dixon (1999), New kinematic models for PacificNorth America motion from 3 Ma to present: 1. Evidence for steady motion and biases in the NUVEL-1A model, Geophys. Res. Lett., 26 , 1921 - 1924, doi:10.1029/1999GL900405.

DiCaprio, C. J., M. Simons, S. J. Kenner, and C. A. Williams (2008), Postseismic reloading and temporal clustering on a single fault, Geophys. J. Int., 172, 581-592, doi:10.1111/j.1365-246X.2007.03622.x.

Dixon, J. E., T. H. Dixon, D. R. Bell, and R. Malservisi (2004), Lateral variation in upper mantle viscosity: Role of water, Earth Planet. Sci. Lett., 222, 451-467, doi:10.1016/j.eps1.2004.03.022.

Dorsey, R. J. (2002), Stratigraphic record of Pleistocene initiation and slip on the Coyote Creek fault, lower Coyote Creek, southern California, in Contributions to Crustal Evolution of the Southwestern United States. Boulder, Colorado, Geol. Soc. Am. Spec. Pap., 365, edited by A. Barth, pp. 251-269, Geol Soc. of Am., Boulder, Colo.

Fay, N. P., and E. D. Humphreys (2005), Fault slip rates, effects of elastic heterogeneity on geodetic data, and the strength of the lower crust in the Salton Trough region, southern California, J. Geophys. Res., 110, B09401, doi:10.1029/2004JB003548.

Fialko, Y. (2006), Interseismic strain accumulation and the earthquake potential of the southern San Andreas fault system, Nature, 441, 968-971, doi:10.1038/nature04797.

Freed, A. M., and R. Bürgmann (2004), Evidence of power-law flow in the Mojave desert mantle, Nature, 430, 548-551, doi:10.1038/nature02784.

Freed, A. M., R. Bürgmann, and T. Herring (2007), Far-reaching transient motions after Mojave earthquakes require broad mantle flow beneath a strong crust, Geophys. Res. Lett., 34, L19302, doi:10.1029/2007GL030959.

Fuis, G. S., D. Scheirer, V. Langenheim, and M. Kohler (2007), The San Andreas fault in southern California is almost nowhere vertical-Implications for tectonics, paper presented at 2007 Annual Meeting, South. Calif. Earthquake Cent., Palm Springs, Calif.

Fumal, T. E., M. J. Rymer, and G. G. Seitz (2002), Timing of large earth quakes since A.D. 800 on the Mission Creek strand of the San Andreas fault zone at Thousand Palms Oasis, near Palm Springs, California, Bull. Seismol. Soc. Am., 92, 2841-2860, doi:10.1785/0120000609.

Heaton, T. H., and D. V. Helmberger (1977), A study of the strong ground motion of the Borrego Mountain, California, earthquake, Bull. Seismol. Soc. Am., 67, 315-330.

Hetland, E. A., and B. H. Hager (2005), Postseismic and interseismic displacements near a strike-slip fault: A two-dimensional theory for general linear viscoelastic rheologies, J. Geophys. Res., 110, B10401, doi:10.1029 2005JB003689.

Hetland, E. A., and B. H. Hager (2006), Interseismic strain accumulation: Spin-up, cycle invariance, and irregular rupture sequences, Geochem. Geophys. Geosyst., 7, Q05004, doi:10.1029/2005GC001087.

Hetland, E. A., M. Simons, and B. H. Hager (2006), Postseismic models consistent with interseismic deformation, Eos Trans. $A G U, 87(52)$, Fall Meet. Suppl., Abstract G33A-0041.

Hilley, G. E., R. Bürgmann, P.-Z. Zhang, and P. Molnar (2005), Bayesian inference of plastosphere viscosities near the Kunlun Fault, northern Tibet, Geophys. Res. Lett., 32, L01302, doi:10.1029/2004GL021658.

Jackson, J. (2002), Strength of the continental lithosphere: Time to abandon the jelly sandwich?, GSA Today, 12, 4-10, doi:10.1130/1052-5173 (2002) $012<0004:$ SOTCLT $>2.0 . \mathrm{CO} ; 2$

Janecke, S. U., R. J. Dorsey, A. N. Steely, A. Lutz, S. M. Kirby, B. A. Housen, and V. Langenheim (2006), Pleistocene initiation of strike-slip faults southwest of the San Andreas fault in southern California: High geologic slip rates due to a southwestward shift of relative plate motion, paper presented at 2006 Annual Meeting, South. Calif. Earthquake Cent., Palm Springs, Calif.

Johnson, H. O., D. C. Agnew, and F. K. Wyatt (1994), Present-day crustal deformation in southern California, J. Geophys. Res., 99, 23,951-23,974.

Johnson, K. M., and P. Segall (2004), Viscoelastic earthquake cycle models with deep stress-driven creep along the San Andreas fault system, J. Geophys. Res., 109, B10403, doi:10.1029/2004JB003096.

Johnson, K. M., G. E. Hilley, and R. Bürgmann (2007), Influence of lithosphere viscosity structure on estimates of fault slip rate in the Mojave region of the San Andreas fault system, J. Geophys. Res., 112, B07408, doi:10.1029/2006JB004842.

Karato, S. (1986), Does partial melting reduce the creep strength of the upper mantle?, Nature, 319, 309-310, doi:10.1038/319309a0. 
Kaufmann, G., and F. Amelung (2000), Reservoir-induced deformation and continental rheology in the vicinity of Lake Mead, Nevada, J. Geophys. Res., 105, 16,341-16,358, doi:10.1029/2000JB900079.

Keller, E. A., M. S. Bonkowski, R. J. Korsch, and R. J. Shlemon (1982), Tectonic geomorphology of the San Andreas fault zone in the southern Indio hills, Coachella Valley, California, Geol. Soc. Am. Bull., 93, 46-56, doi:10.1130/0016-7606(1982)93<46:TGOTSA > 2.0.CO;2.

Kendrick, K. J., D. M. Morton, S. G. Wells, and R. W. Simpson (2002), Spatial and temporal deformation along the northern San Jacinto fault, southern California: Implications for slip rates, Bull. Seismol. Soc. Am., 92, 2782-2802, doi:10.1785/0120000615.

Kirby, S. M., S. U. Janecke, R. J. Dorsey, B. A. Housen, V. E. Langenheim, K. A. McDougall, and A. N. Steely (2007), Pleistocene Brawley and Ocatillo formations: Evidence for initial strike-slip deformation along the San Felipe and San Jacinto fault zones, southern California, J. Geol., 115, 43-62, doi:10.1086/509248.

Kohler, M. D., H. Magistrale, and R. W. Clayton (2003), Mantle heterogeneities and the SCEC reference three-dimensional seismic velocity model version 2, Bull. Seismol. Soc. Am., 93, 757-774, doi:10.1785 0120020017

Lachenbruch, A. H., J. H. Sass, and S. P. Galanis Jr. (1985), Heat flow in southernmost California and the origins of the Salton Trough, J. Geophys. Res., 90, 6709-6736, doi:10.1029/JB090iB08p06709.

Lanari, R., P. Lundgren, M. Manzo, and F. Casu (2004), Satellite interferometry time series analysis of surface deformation for Los Angeles, California, Geophys. Res. Lett., 31, L23613, doi:10.1029/2004GL021294.

Langenheim, V. E., R. C. Jachens, D. M. Morton, R. W. Kistler, and J. C. Matti (2004), Geophysical and isotopic mapping of preexisting crustal structures that influenced the location and development of the San Jacinto fault zone, southern California, Geol. Soc. Am. Bull., 116, 1143-1157, doi:10.1130/B25277.1

Le, K., and M. Oskin (2007), Temporal slip rate variability along the southern San Jacinto fault, paper presented at 2007 Annual Meeting, South. Calif. Earthquake Cent., Palm Springs, Calif.

Le Pichon, X., C. Kreemer, and N. Chamot-Rooke (2005), Asymmetry in elastic properties and the evolution of large continental strike-slip faults, J. Geophys. Res., 110, B03405, doi:10.1029/2004JB003343.

Li, Q., and M. Liu (2007), Initiation of the San Jacinto fault and its interaction with the San Andreas fault: Insights from geodynamic modeling, Pure Appl. Geophys., 164, 1937-1945, doi:10.1007/s00024-007-0262-z.

Lin, G., P. M. Shearer, E. Hauksson, and C. H. Thurber (2007), A threedimensional crustal seismic velocity model for southern California from a composite event method, J. Geophys. Res., 112, B11306, doi:10.1029/ 2007JB004977.

Lutz, A. T., R. J. Dorsey, B. A. Housen, and S. U. Janecke (2006), Stratigraphic record of Pleistocene faulting and basin evolution in the Borrego Badlands, San Jacinto fault zone, southern California, Geol. Soc. Am. Bull., 118, 1377-1397, doi:10.1130/B25946.1.

Magistrale, H. (2002), Relative contributions of crustal temperature and composition to controlling the depth of earthquakes in Southern California, Geophys. Res. Lett., 29(10), 1447, doi:10.1029/2001GL014375.

Magistrale, H., and T. Rockwell (1996), The central and southern Elsinore fault zone, southern California, Bull. Seismol. Soc. Am., 86, 1793-1803.

Malservisi, R., K. P. Furlong, and T. H. Dixon (2001), Influence of the earthquake cycle and lithospheric rheology on the dynamics of the Eastern California Shear Zone, Geophys. Res. Lett., 28(14), 2731-2734, doi:10.1029/2001GL013311.

McGill, S., et al. (2002), Paleoseismology of the San Andreas fault at Plunge Creek, near San Bernardino, southern California, Bull. Seismol. Soc. Am., 92, 2803-2840, doi:10.1785/0120000607.

Meade, B. J., and B. H. Hager (2005), Block models of crustal motion in southern California constrained by GPS measurements, J. Geophys. Res., 110, B03403, doi:10.1029/2004JB003209.

Nazareth, J. J., and E. Hauksson (2004), The seismogenic thickness of the southern California crust, Bull. Seismol. Soc. Am., 94, 940-960, doi: $10.1785 / 0120020129$

Parsons, T. (2008), Monte Carlo method for determining earthquake recurrence parameters from short paleoseismic catalogs: Example calculations for California, J. Geophys. Res., 113, B03302, doi:10.1029/2007JB004998.

Petersen, M. D., and S. G. Wesnousky (1994), Fault slip rates and earthquake histories for active faults in southern California, Bull. Seismol. Soc. Am., 84, 1608-1649.

Pollitz, F. F. (2001), Viscoelastic shear zone model of a strike-slip earthquake cycle, J. Geophys. Res., 106, 26,541-26,560, doi:10.1029/2001JB000342.

Pollitz, F. F., C. Wicks, and W. Thatcher (2001), Mantle flow beneath a continental stick-slip fault: Postseismic deformation after the 1999 Hector Mine earthquake, Science, 293, 1814-1818, doi:10.1126/science.1061361.
Rockwell, T. K., C. Loughman, and P. Merifield (1990), Late Quaternary rate of slip along the San Jacinto fault zone near Anza, southern California, J. Geophys. Res., 95, 8593-8605, doi:10.1029/JB095iB06p08593.

Rockwell, T. K., et al. (2003), 3,000 years of ground-rupturing earthquakes in the Anza seismic gap, San Jacinto fault, southern California: Time to shake it up?, Seismol. Res. Lett., 74, 236-237.

Rockwell, T. K., et al. (2006), The long record of San Jacinto Fault paleoearthquakes at Hog Lake: Implications for regional patterns of strain release in the southern San Andreas Fault system, Seismol. Res. Lett., 77, 270.

Rosen, P. A., S. Hensley, I. R. Joughin, F. K. Li, S. N. Madsen, E. Rodriguez, and R. M. Goldstein (2000), Synthetic aperture radar interferometry, Proc. IEEE, 88, 333-382, doi:10.1109/5.838084.

Savage, J. C., and R. O. Burford (1973), Geodetic determination of relative plate motion in central California, J. Geophys. Res., 78, 832-845, doi:10.1029/JB078i005p00832.

Savage, J. C., and W. H. Prescott (1978), Asthenosphere readjustment and the earthquake cycle, J. Geophys. Res., 83, 3369-3376, doi:10.1029/ JB083iB07p03369.

Schmalzle, G., T. Dixon, R. Malservisi, and R. Govers (2006), Strain accumulation across the Carrizo segment of the San Andreas fault California: Impact of laterally varying crustal properties, J. Geophys. Res., 111, B05403, doi:10.1029/2005JB003843.

Sharp, R. V. (1981), Variable rates of late Quaternary strike slip on the San Jacinto fault zone, southern California, J. Geophys. Res., 86, 1754-1762, doi:10.1029/JB086iB03p01754.

Shen, Z.-K. (2001), Southern California Earthquake Center crustal motion map version 3.0, Eos Trans. AGU, 82(47), Fall Meet. Suppl., Abstract G41A-0206.

Shen, Z.-K., D. D. Jackson, and B. X. Ge (1996), Crustal deformation across and beyond the Los Angeles basin from geodetic measurements, J. Geophys. Res., 101(B12), 27,957-27,980, doi:10.1029/96JB02544

Shifflett, H., M. G. Gray, R. Grannell, and B. L. Ingram (2002), New evidence on the slip rate, renewal time, and late Holocene surface displacement, southernmost San Andreas fault, Mecca hills, California, Bull. Seismol. Soc. Am., 92, 2861 - 2877, doi:10.1785/0120000601.

Sieh, K. (1986), Slip rates across the San Andreas fault and prehistoric earthquakes at Indio, California, EOS Trans. AGU, 67, 1200.

Sieh, K. E., and P. L. Williams (1990), Behavior of the southernmost San Andreas fault during the past 300 years, J. Geophys. Res., 95, 6629-6645, doi:10.1029/JB095iB05p06629.

Thatcher, W., and F. F. Pollitz (2008), Temporal evolution of continental lithospheric strength in actively deforming regions, Geol. Soc. Am. Bull., 18, 4-11, doi:10.1130/GSAT01804-5A.1.

Thomas, A. P., and T. K. Rockwell (1996), A 300- to 500-year history of slip on the Imperial fault near the U.S.-Mexico border: Missing slip at the Imperial fault bottleneck, J. Geophys. Res., 101, 5987-5997, doi:10.1029/ 95JB01547.

van der Woerd, J., Y. Klinger, K. Sieh, P. Tapponnier, F. J. Ryerson, and A.-S. Mériaux (2006), Long-term slip rate of the southern San Andreas fault from ${ }^{10} \mathrm{Be}-{ }^{26} \mathrm{Al}$ surface exposure dating of an offset alluvial fan, J. Geophys. Res., 111, B04407, doi:10.1029/2004JB003559.

Vaughan, P. R., K. M. Thorup, and T. K. Rockwell (1999), Paleoseismology of the Elsinore fault at Agua Tibia mountain, southern California, Bull. Seismol. Soc. Am., 89, 1447-1457.

Weldon, R. J., and K. E. Sieh (1985), Holocene rate of slip and tentative recurrence interval for large earthquakes on the San Andreas fault, Cajon Pass, southern California, Geol. Soc. Am. Bull., 96, 793 -812, doi:10.1130/ 0016-7606(1985)96<793:HROSAT>2.0.CO;2.

Wessel, P., and W. H. F. Smith (1995), New version of the Generic Mapping Tools released, Eos Trans. AGU, 76, 329, doi:10.1029/95EO00198, [version 3.0].

Williams, C. A., and R. M. Richardson (1991), A rheologically layered three-dimensional model of the San Andreas fault in central and southern California, J. Geophys. Res., 96, 16,597-16,623, doi:10.1029/91JB01484.

Yan, Z., and R. W. Clayton (2007), Regional mapping of the crustal structure in southern California from receiver functions, J. Geophys. Res., 112, B05311, doi:10.1029/2006JB004622.

E. J. Fielding, Z. Liu, and P. Lundgren, Jet Propulsion Laboratory, California Institute of Technology, 4800 Oak Grove Drive, Pasadena, CA 91109, USA. (paul.r.lundgren@jpl.nasa.gov)

E. A. Hetland, Department of Geological Sciences, University of Michigan, 1100 North University Avenue, Ann Arbor, MI 48109, USA. (ehetland@alum.mit.edu) 